\title{
Development of the First Covalent Monopolar Spindle Kinase 1 (MPS1/TTK) Inhibitor
}

Ricardo A. M. Serafim ${ }^{1,2,3 \#}$, André S. Santiago ${ }^{2,3 \#}$, Caio V. dos Reis ${ }^{2,3}$, Jessica E. Takarada ${ }^{2,3}$, Priscila Mezzomo ${ }^{2,3}$, Katlin B. Massirer ${ }^{2,3}$, Martin P. Schwalm ${ }^{4,5}$, Mark Kudolo ${ }^{1}$, Stefan Gerstenecker ${ }^{1}$, Apirat Chaikuad ${ }^{4,5}$, Stefan Knapp ${ }^{4,5,6}$, Stefan Laufer ${ }^{1,7,8}$, Rafael M. Couñago ${ }^{2,3^{*}}$, Matthias Gehringer ${ }^{1,7^{*}}$

${ }^{1}$ Department of Pharmaceutical/Medicinal Chemistry, Eberhard Karls University Tübingen, Auf der Morgenstelle 8, 72076 Tübingen, Germany

${ }^{2}$ Centro de Química Medicinal (CQMED), Centro de Biologia Molecular e Engenharia Genética (CBMEG), Universidade Estadual de Campinas (UNICAMP), Campinas, SP, 13083-875, Brazil

${ }^{3}$ Structural Genomics Consortium, Departamento de Genética e Evolução, Instituto de Biologia, UNICAMP, Campinas, SP, 13083-886, Brazil

${ }^{4}$ Structural Genomics Consortium, Goethe University Frankfurt, Buchmann Institute for Molecular Life Sciences, Max-von-Laue-Straße 15, 60438 Frankfurt am Main, Germany

${ }^{5}$ Institute of Pharmaceutical Chemistry, Goethe University Frankfurt, Buchmann Institute for Molecular Life Sciences, Max-von-Laue-Straße 9, 60438 Frankfurt am Main, Germany

${ }^{6}$ Frankfurt Cancer Institute $(\mathrm{FCl})$ and German translational cancer network (DKTK) site Frankfurt/Mainz, Frankfurt am Main, Germany

7 Cluster of Excellence iFIT (EXC 2180) 'Image-Guided \& Functionally Instructed Tumor Therapies', University of Tübingen, 72076 Tübingen, Germany

${ }^{8}$ Tübingen Center for Academic Drug Discovery, Auf der Morgenstelle 8, 72076 Tübingen, Germany

"Equal contribution; *Correspondence

rafael.counago@unicamp.br

matthias.gehringer@uni-tuebingen.de

\section{Keywords}

Monopolar spindle kinase 1, spindle assembly checkpoint, covalent inhibitors, cysteinome, protein kinases, chemical probes, structure-based design. 


\begin{abstract}
Monopolar spindle kinase 1 (MPS1/TTK) is a key element of the mitotic checkpoint securing proper chromosome segregation. It is being evaluated as a target in the treatment of aggressive tumors such as triple-negative breast cancer with several reversible inhibitors currently undergoing clinical trials. While long drug-target residence times have been suggested to be beneficial in the context of therapeutic MPS1 inhibition, no irreversible inhibitors are known. Here we present the design and characterization of the first irreversible covalent MPS1 inhibitor RMS-07 targeting a cysteine (Cys604) in the kinase's hinge region present only in few other protein kinases. The compound showed excellent MPS1 inhibitory potency and high selectivity against all protein kinases harboring an equivalent cysteine as well as in a larger differential scanning fluorimetry-based screening panel. Covalent binding was confirmed by mass spectrometry and X-ray crystal structure. We expect this tool compound to open new avenues for the design of MPS1-specific covalent chemical probes or drugs.
\end{abstract}




\section{Introduction}

The monopolar spindle kinase 1 (MPS1, also known as TTK) plays a critical role in controlling cell division and is a key component of the spindle assembly checkpoint (SAC). During mitosis and meiosis, the SAC acts to ensure proper chromosome segregation by delaying cell division until sister chromatids are pulled to opposite ends of the dividing cell. MPS1 phosphorylates the threonine residue found within MELT repeats in the N-terminal portion of the Kinetochore Scaffold 1 protein (Knl1). This event recruits the Bub proteins including the mitotic checkpoint protein BUB3 and mitotic checkpoint serine/threonine-protein kinases BUB1 and BUBR1 to the SAC, activating it ${ }^{1-3}$. MPS1 may also participate in chromosome segregation error correction by activating Aurora B kinase, a major orchestrator of the SAC ${ }^{4}$. MPS1 overexpression has been linked to poor prognosis in a variety of solid tumors, including glioblastoma, triple-negative breast and pancreatic cancer. Indeed, elevated MPS1 protein levels have been suggested as a prognostic marker for neuroblastoma ${ }^{4-8}$.

Inhibition of MPS1 by small molecules is a promising approach in cancer therapy, with the mechanism of action of SAC inactivation being complementary to that of Taxol and vinca alkaloids, i.e. overriding the SAC to cause accumulation of chromosome segregation errors which lead to cancer cell death by apoptosis ${ }^{8-11}$. Several reversible MPS1 inhibitors, including BAY 1161909 (Empesertib, 1) $)^{11}$, BAY $1217389(2)^{11}$, BOS172722 (3) $)^{12}$ and CFI-402257 (4) ${ }^{13}$ (Figure 1A) are currently undergoing clinical trials.

A
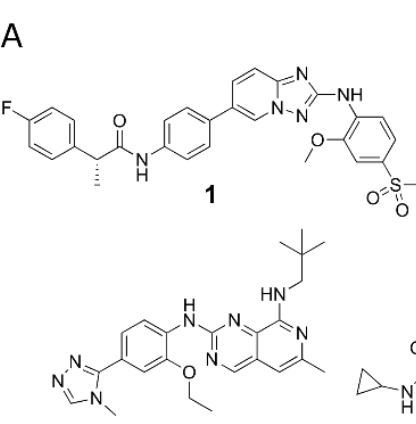
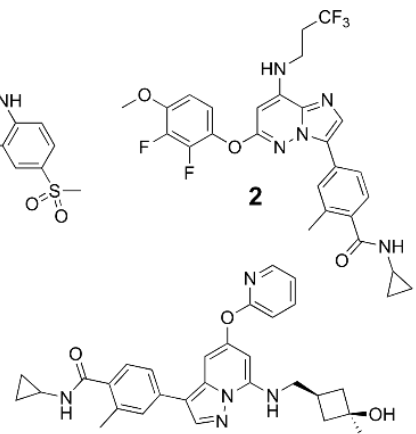

4
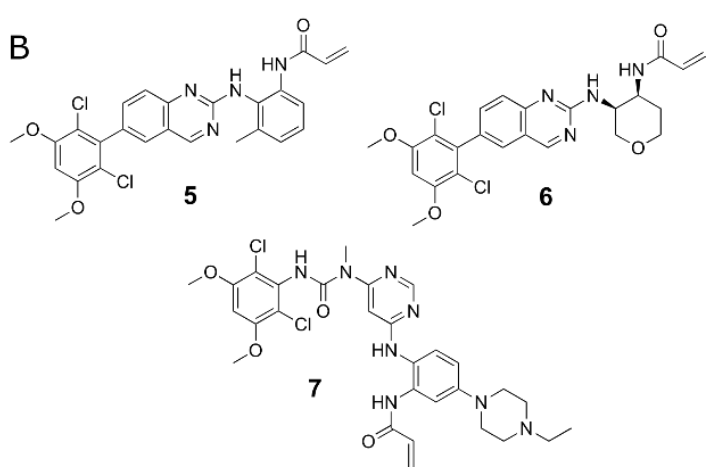

Figure 1: A Reversible MPS1 kinase inhibitors in clinical trials. B Covalent FGFR4 kinase inhibitors.

Typically, early drug discovery projects focus on improving compound potency under equilibrium conditions and are guided by parameters like $\mathrm{IC}_{50}$ or $K_{\mathrm{D}}{ }^{14}$. Nevertheless, in living 
systems, a compound's concentration is continuously changing, as it is subjected to drug metabolism and excretion. In this context, it has been suggested that target residence time $(\tau$; defined as the inverse of the dissociation rate constant $\left.k_{\text {off }}\right)$ is a more appropriate metric to rank and prioritize compounds during hit and lead optimization campaigns ${ }^{15}$. Moreover, compounds with long on-target residence times may also be more selective and may have fewer side-effects. In general, the fraction of long residence kinase inhibitors increases from early/preclinical to late stage and FDA-approved compounds, suggesting favorable contributions of slow off-rates to clinical success ${ }^{16}$. In the case of MPS1, it has been suggested that prolonged inhibition of SAC activity by inhibitors with long residence times might be more efficacious than discontinuous blockage by compounds with faster off-kinetics. This hypothesis, however, requires further investigation, ideally with very slow off-rate or irreversible inhibitors. It is also important to keep in mind that in vivo, potency or target residence time are not the only factors to be considered, and that pharmacokinetics and target turnover are also important determinants of the duration of pharmacological action ${ }^{17}$.

Covalent targeting approaches provide an excellent opportunity to extend residence time, but reactive groups have long suffered from a bad reputation among drug discovery scientist due to potential adverse effects resulting from off-target labeling or immunogenicity triggered by haptenization. During the last decade, however, covalent drugs have resurged due to increasing awareness that well-designed covalent inhibitors can have advantages regarding potency, selectivity, and kinetic profile ${ }^{18}$. Their durable target engagement may translate into lower and less frequent dosing which can even decrease side effect burden ${ }^{18,19}$. Covalent approaches have lately been very successful in protein kinase inhibitor discovery ${ }^{20-22}$. The more than 500 protein kinases encoded in the human genome, referred to as the "kinome", feature a high degree of conservation making the design of specific protein kinase inhibitors a challenging task. Traditionally, inhibitor design exploited less conserved regions in the ATP binding site or conformations unique to the kinase(s) of interest. More recently, covalent targeting of poorly conserved non-catalytic cysteines, that are present inside or in close proximity to the ATP binding pocket in approximately half of the kinome, has successively gained importance as a design strategy to obtain highly selective inhibitors ${ }^{20}$. Here, two orthogonal selectivity filters can be exploited, i.e. reversible recognition and the requirement of a cysteine at a specific location to enable covalent bond formation. This approach has facilitated the design of highly specific covalent chemical probes but also drugs as highlighted by seven covalent kinase inhibitors currently approved by the FDA ${ }^{23}$. Design of covalent ligands typically starts from structural information of a non-reactive template inhibitor enabling the identification of suitable 
attachment points for a weakly reactive moiety, often referred to as "warhead", to specifically hit the cysteine of interest ${ }^{24}$. This and other strategies to identify covalent protein kinase inhibitors have been reviewed elsewhere ${ }^{21,25}$.

The MPS1 kinase harbors a cysteine (Cys604) in the central hinge region, located two residues $\mathrm{N}$-terminal to the gatekeeper (GK) residue (i.e. in the $\mathrm{GK}+2$ position). Such a cysteine is only presented in four other kinases in the human kinome, namely FGFR4, p70S6K $\beta$ (S6K2), MAPKAPK2 (МK2) and MAPKAPK3 (MK3) 20,22. In a recent study, Uitdehaag and colleagues highlighted the crucial importance of long residence time for the cellular (and presumable also in vivo) efficacy of MPS1 inhibitors ${ }^{26}$. This prompted us to investigate a covalent-irreversible targeting strategy as the ultimate way to increase residence time. Based on the aforementioned structural information, we concluded that targeting the GK+2 cysteine might at the same time improve selectivity, since this residue occurs in only very few kinases. Given the importance of this kinase as an attractive novel drug target, we decided to approach a proof-of-concept study for inhibiting the MPS1 covalently for the first time.

\section{Results and discussion}

Design. Our approach started from available reversible inhibitors with known binding modes $^{11,26-29}$ that were to be equipped with a suitable linker to direct a reactive acrylamide towards MPS1-Cys604. A similar strategy has previously been successfully applied for the fibroblast growth factor receptor (FGFR) 4 kinase, exemplified by the prototype inhibitor BLU9931 (5, Figure 1B $)^{30}$. In the latter compound, an ortho-phenylenediamine linker forming a dual hydrogen bond towards a backbone carbonyl atom in the hinge region was used to induce a U-shaped conformation directing the warhead towards the $\mathrm{GK}+2$ cysteine. The same strategy was also employed in several follow-up FGFR4 inhibitors, including the clinical candidates

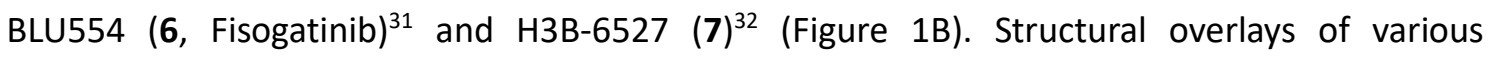
MPS1/inhibitor complexes with the BLU9931/FGFR4 complex suggested inhibitor NTRC 0066-0 $(8$, Figure $2 \mathrm{~A})$ as a promising starting point for our endeavor. According to the co-crystal structure of compound 8 in complex with MPS1 (Figure 2B), the ortho-methoxy group of the front pocket residue, which is known as an important selectivity driver in this and several other MPS1 inhibitors, is located in close proximity to the target cysteine and aligns well with the warhead portion in the overlay with BLU9931/FGFR4 (Figure 2C) ${ }^{26,33}$. Additionally, covalent docking studies were performed (data not shown) suggesting that an acrylamide warhead could reach the desired cysteine in a favorable conformation resembling the one of the BLU9931/FGFR4 complex. These results encouraged us to replace the methoxy group in compound 8 by an acrylamide warhead to obtain the putative covalent inhibitor RMS-07 (9, Figure 2A). 
A Covalent inhibitor design<smiles>CCc1cccc(CC)c1NC(=O)c1ccn2c1CCc1cnc(Nc3ccc(N4CCN(C)CC4)cc3OC)nc1-2</smiles><smiles></smiles>

B

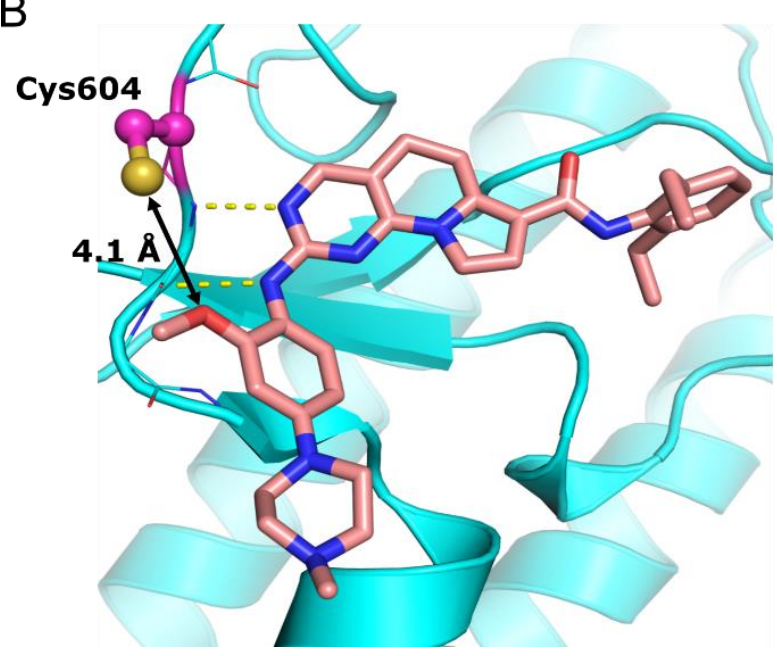

C

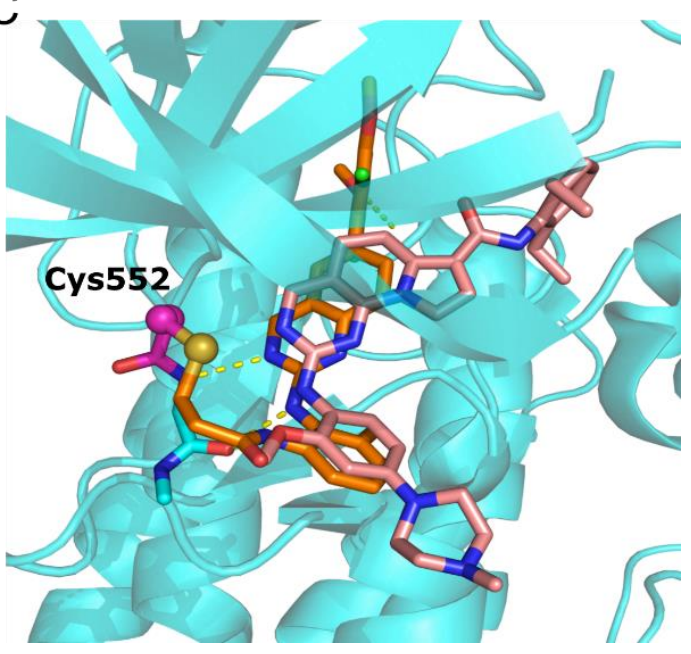

Figure 2: A Design of the putative covalent inhibitor RMS-07 (9) by replacement of the methoxysubstituent of NTRC 0066-0 (8) with an acrylamide warhead (highlighted in red). B Co-crystal structure of the complex of MPS1 and template inhibitor 8 (PDB code: 5N87) showing the proximity between Cys604 and the inhibitor's methoxy group. C Overlay of BLU9931/FGFR4 (orange/cyan, Cys552 highlighted in magenta, PDB code: 4XCU) and compound 8/MPS1 (salmon). Only the FGFR4 backbone is shown and water-mediated hydrogen bonds were omitted for clarity.

Chemistry. The synthesis of the designed inhibitor RMS-07 (Scheme 1) started with the preparation of the precursor of the ortho-phenylenediamine fragment (12), which was to be linked to the core scaffold (13) via Buchwald-Hartwig arylamination. To this end, aniline derivative 10 was double Boc-protected followed by Buchwald-Hartwig arylamination with $N$ methylpiperazine. Acid-promoted deprotection of the aniline furnished intermediate 12 in good overall yield. The latter was connected via another Buchwald-Hartwig reaction with key intermediate 13, which was prepared according to literature procedures ${ }^{34,35}$ and obtained as a mixture of the methyl and the ethyl ester. The coupling product was subjected ester cleavage using $\mathrm{LiOH}$ to obtain the free carboxylic acid 14. Acid activation was subsequently performed by thionyl chloride and reaction of the ensuing acyl chloride with 2,6-diethylaniline in the presence of DMAP yielded the desired amide 15. Notably, various other amide coupling protocols failed to deliver the coupling product in acceptable yields (not shown). Reduction of the nitro group 
with tin(II) chloride furnished ortho-phenylenediamine derivative 16. In the last step, the acrylamide warhead was introduced by acylation of $\mathbf{1 6}$ with acryloyl chloride in the presence of DIPEA at low temperatures to obtain final compound RMS-07.
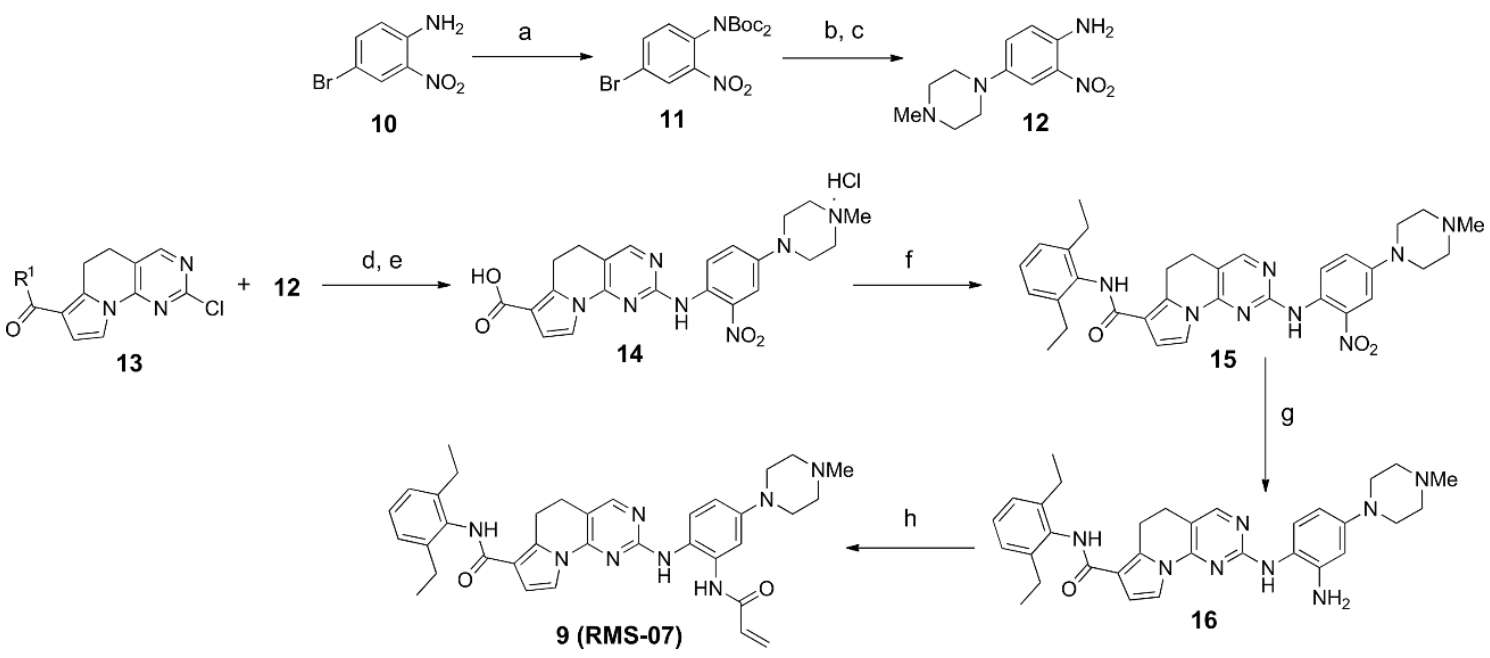

Scheme 1: Synthetic route to leading to RMS-07 (9). Reagents and conditions: $R^{1}$ : mixture of OMe/OEt. a) $\mathrm{Boc}_{2} \mathrm{O}, \mathrm{DMAP}, \mathrm{THF}, 65{ }^{\circ} \mathrm{C}, 12 \mathrm{~h}, 93 \%$. b) $\mathrm{N}$-methylpiperazine, SPhosPdG3, $\mathrm{Cs}_{2} \mathrm{CO}_{3}$, 1,4-dioxane, $105^{\circ} \mathrm{C}, 12$ h. c) TFA, DCM, r.t., 3 h, 64\% (two steps). d) BrettPhosPdG3, $\mathrm{Cs}_{2} \mathrm{CO}_{3}, 1,4-$ dioxane/tBuOH (4:1), $110{ }^{\circ} \mathrm{C}, 7 \mathrm{~h}$. e) $\mathrm{LiOH} \cdot \mathrm{H}_{2} \mathrm{O}, \mathrm{THF} / \mathrm{H}_{2} \mathrm{O} / \mathrm{MeOH}(2: 1: 1), 50{ }^{\circ} \mathrm{C}, 12 \mathrm{~h}$, then $\mathrm{HCl}$ (2 M), 67\% (two steps). f) $\mathrm{SOCl}_{2}, \mathrm{DCM}, 0{ }^{\circ} \mathrm{C}$-r.t., $48 \mathrm{~h}$, then 2,6-diethylaniline, ACN, DMAP, $65^{\circ} \mathrm{C}$, $86 \%$. g) $\mathrm{SnCl}_{2}$, EtOH/THF (2:1), $65^{\circ} \mathrm{C}, 3 \mathrm{~h}, 95 \%$. h) acryloyl chloride, DIPEA, DMF, $-10{ }^{\circ} \mathrm{C}-$ r.t., $66 \%$.

Protein Biochemistry. To evaluate the inhibitory potency of RMS-07, we set up an enzymatic assay based on time-resolved fluorescence resonance energy transfer (TR-FRET) using commercially available full-length MPS1, and a generic kinase peptide substrate based on the human Histone H3 sequence (ARTKQTARKSTGGK, underline indicates phosphorylated residue). In cells, Histone $\mathrm{H} 3$ is not thought to be phosphorylated by MPS $1^{13}$. Nevertheless, in vitro, the enzyme displayed robust phosphorylation activity of this peptide substrate (Supplementary Figure $\mathrm{S} 1 \mathrm{~A}$ ). Using this assay, we determined the enzyme $K_{\mathrm{M}, \mathrm{ATP}}$ to be $9.73 \mu \mathrm{M}$ (Supplementary Figure S1B), which is in good agreement with previously reported values $(5.0 \mu \mathrm{M})$ obtained using fluorescence polarization to measure MPS1 phosphorylation of a different peptide substrate ${ }^{36}$. We next used this assay to determine the inhibitory potency of RMS-07 against full-length MPS1. As formation of a covalent bond is a time-dependent process impacting $\mathrm{IC}_{50}$ measurements (see below), we omitted the typical compound-protein pre-incubation step prior to starting the enzymatic reaction. For these initial experiments, we also omitted the addition of the DTT reducing agent to the kinase buffer. Due to the high compound potency, experiments were carried out at high ATP concentrations (approx. 15-fold $K_{\mathrm{M}, \mathrm{ATP}}$ ). Under these conditions, RMS-07 showed an apparent $I C_{50}$ of $13.1 \mathrm{nM}$ (Figure $3 \mathrm{~A}$ ). Since the $\mathrm{IC}_{50}$ depends on experimental conditions including enzyme and substrate concentrations, we used the Cheng-Prusoff equation 
to derive an apparent $K_{\mathrm{i}}$ value ${ }^{37}$. Notably, the value obtained for inhibitor RMS-07 (apparent $K_{\mathrm{i}}=$ $0.83 \mathrm{nM}$ ) under the given (non-equilibrium) conditions is in the same range as reference value published for compound $\mathbf{8}\left(K_{\mathrm{i}}=0.30 \mathrm{nM}\right)$ determined in a different setup ${ }^{36}$.

A

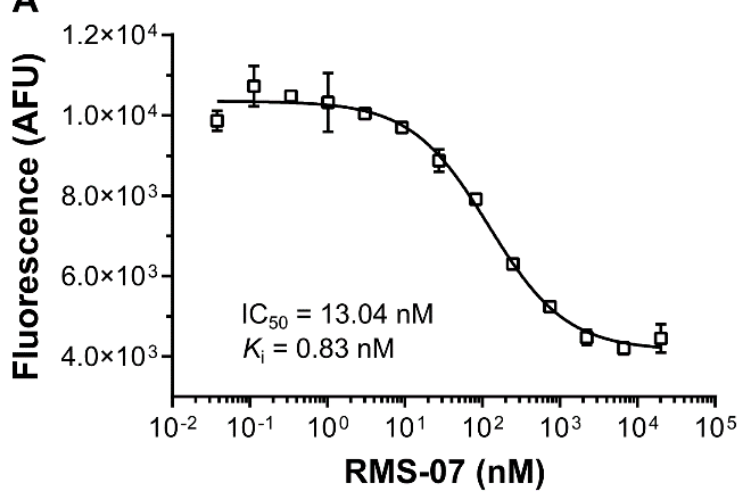

B

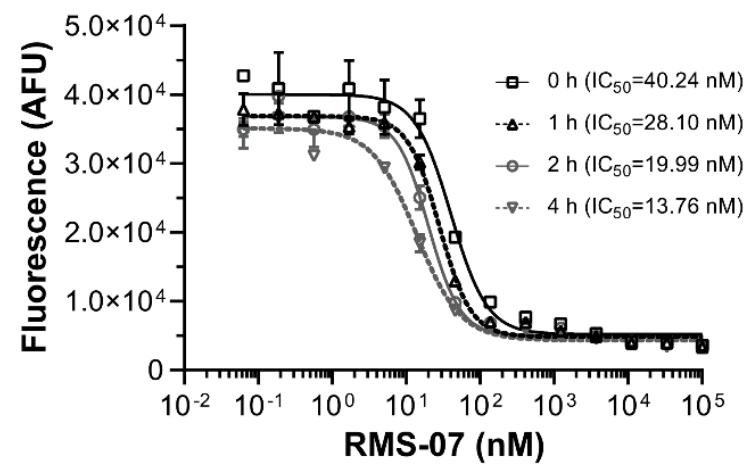

C

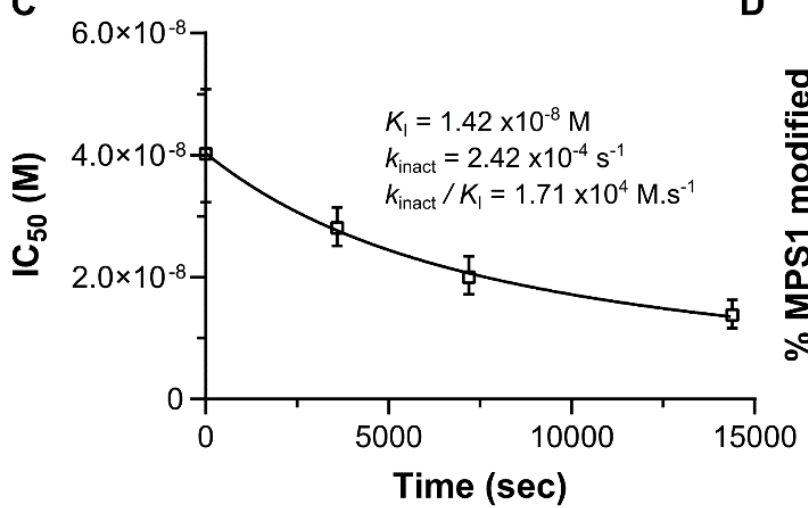

D

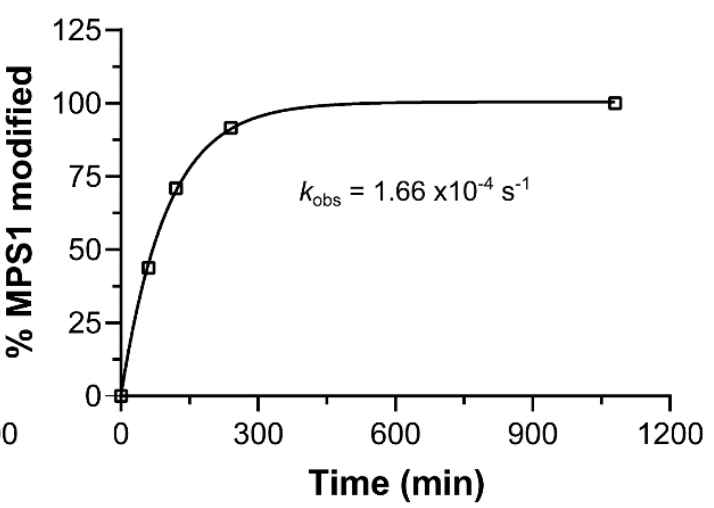

Figure 3 - Biochemical characterization of RMS-07, a covalent MPS1 inhibitor. A,B $I_{50}$ determination. Graphs show the concentration-dependent inhibition of full-length MPS1 activity by RMS-07. $\mathrm{IC}_{50}$ values were obtained by fitting the experimental data (shown as mean \pm s.e.m. of two independent measurements) to a sigmoidal dose-response (variable slope) equation. In A, pre-incubation and DTT as a buffer component were omitted. The $K_{\mathrm{i}}$ value shown was calculated using the Cheng-Prusoff formalism. In panel $\mathbf{B}$, dose response curves were obtained following pre-incubation of full-length MPS1 with RMS-07 for 0, 1, 2, and 4 hours in DTT-containing buffer. Calculated I $\mathrm{C}_{50}$ values are shown for each time point. $\mathrm{C}$ Determination of the second-order rate constant $k_{\text {inact }} / K_{\mathrm{I}}$ by fitting the data shown in panel $\mathrm{B}$ according to Krippendorff and colleagues ${ }^{38}$. D Time-course of the covalent modification of the MPS1 kinase domain by excess RMS-07 determined by LC-MS. The pseudo-first order association rate constant $\left(k_{\text {obs }}\right)$ was obtained by fitting the experimental data to a one-phase association model.

As mentioned, a key characteristic of irreversible covalent inhibitors is that their $\mathrm{IC}_{50}$ values decrease with increasing target exposure times. This behavior arises from covalent inhibition being a two-step non-equilibrium process where an initial reversible protein-ligand binding event is followed by the formation of a long-lived covalent bond. This process is described by two parameters, namely $K_{1}$ and $k_{\text {inact. }}$. Here, the constant $K_{1}$ (not to be confused with the binding constant $K_{\mathrm{i}}$ obtained above assuming equilibrium conditions) reflects the compound 
concentration at which the rate of covalent inactivation becomes half-maximal $\left(k_{\text {inact }} / 2\right)$. The second parameter, $k_{\text {inact, }}$ is a first-order rate constant defining the maximal potential rate of covalent inactivation ${ }^{24,39}$. The ratio $k_{\text {inact }} / K_{1}$ is a second-order rate constant that reflects the overall inactivation efficiency and is considered the appropriate metric to compare the activity of irreversible covalent inhibitors ${ }^{40}$.

To quantify $k_{\text {inact }}$ and $K_{1}$ for RMS-07, we determined $I_{50}$ values at different pre-incubation times (0, 1, 2, 4 hours). Importantly, this setup required the addition of DTT as a reducing agent, which led to a shift in the initial $I C_{50}$ value ( $40 \mathrm{nM}$ vs. $13 \mathrm{nM}$ for $\mathrm{t}=0$ ) that we cannot fully rationalize so far. The data obtained was in accordance with the expected covalent mode-ofaction since longer pre-incubation times increased potency (Figure 3B). By fitting the experimental data according to Krippendorff and colleagues ${ }^{38}$, we obtained $k_{\text {inact }}\left(2.42 \times 10^{-4} \mathrm{~s}^{-}\right.$ $\left.{ }^{1}\right)$ and $K_{1}\left(14.2 \times 10^{-9} \mathrm{M}\right)$ resulting in a $k_{\text {inact }} / K_{1}$ ratio of $1.71 \times 10^{4} \mathrm{M}^{-1} \cdot \mathrm{s}^{-1}$ (Figure $\left.3 \mathrm{C}\right)$. For comparison, covalent EGFR kinase inhibitors currently in clinical use have 10 - to 1,000 -fold larger $k_{\text {inact }} / K_{\text {I }}$ ratios (Supplementary Table S1) ${ }^{41}$.

To further characterize RMS-07's interaction with MPS1, we expressed and purified a truncated version of the protein including only the kinase domain (residues Ser519 to Glu808; hereafter denominated MPS1-KD). Intact mass analysis of purified MPS1-KD using liquid chromatography-mass spectrometry (LC-MS) confirmed the protein mass of 36,064.4 Da (Supplementary Figure S2A,B,C) and exposure to RMS-07 produced the mass shift (604.8 Da) expected for adduct formation (Supplementary Figure S2C). The same method was used to investigate the time course of adduct formation. Under pseudo-first order conditions employing a 10-fold excess RMS-07 over MPS1-KD, modification was followed over 18 hours and the resulting data was fitted to a one-phase association model to obtain the pseudo-first order association rate constant ( $\left.k_{\mathrm{obs}}\right)$. These analyses gave a $k_{\mathrm{obs}}$ value of $1.66 \times 10^{-4} \mathrm{~s}^{-1}$ (Figure 3D), which is in good agreement with the $k_{\text {inact }}$ value derived from the enzymatic assays $\left(2.42 \times 10^{-4}\right.$ $\left.\mathrm{s}^{-1}\right)$. Reaction half-time was determined to 69.8 minutes. Taken together, biochemical characterization confirmed RMS-07 to be a potent, covalent MPS1 inhibitor albeit with comparably slow inactivation kinetics.

Protein Crystallography. To characterize the interaction between RMS-07 and MPS1 at a molecular level, we obtained the co-crystal structure of MPS1-KD bound to RMS-07 at $2.0 \AA$. The co-structure was solved by molecular replacement (Supplementary Table S2). As expected, MPS1-KD adopted the archetypical kinase fold with an N-terminal lobe composed mostly of $\beta$ strands (residues 519-601), a C-terminal lobe formed predominantly by $\alpha$-helices (residues 608 - 
697) and a hinge region (residues 602-607) connecting the lobes (Figure 4A). RMS-07 occupied the ATP-binding site located between the two lobes (Figure 4A-E). The high quality of the electron density map allowed for unambiguous modelling of RMS-07. Continuous electron density was observed for the covalent $\mathrm{C}-\mathrm{S}$ bond between the Cys604 thiol and the (reacted) RMS-07 acrylamide group (Figure 4F, G). The carbonyl oxygen of the ligand's former acrylamide moiety also engages in a hydrogen bond to the side chain of Gln541 while its amide $\mathrm{N}-\mathrm{H}$ interacts with the backbone carbonyls of Gly605 and Asn606. Those interactions may assist in directing the warhead towards Cys604 prior to the reaction. As expected, the Gly605 carbonyl oxygen forms another hydrogen bond to the RMS-07 aminopyrimidine $\mathrm{N}-\mathrm{H}$ while the pyrimidine $\mathrm{N} 1$ atom binds to the Gly605 backbone $\mathrm{N}-\mathrm{H}$. The amide moiety at the opposite side of the ligand forms a hydrogen bond to the (protonated) side chain amino group of the catalytic Lys553 and to a crystallographic water molecule. Moreover, Lys553 interacts with the terminal diethyl phenyl moiety of RMS-07 via a cation- $\pi$ interaction (Figure 4D, E).
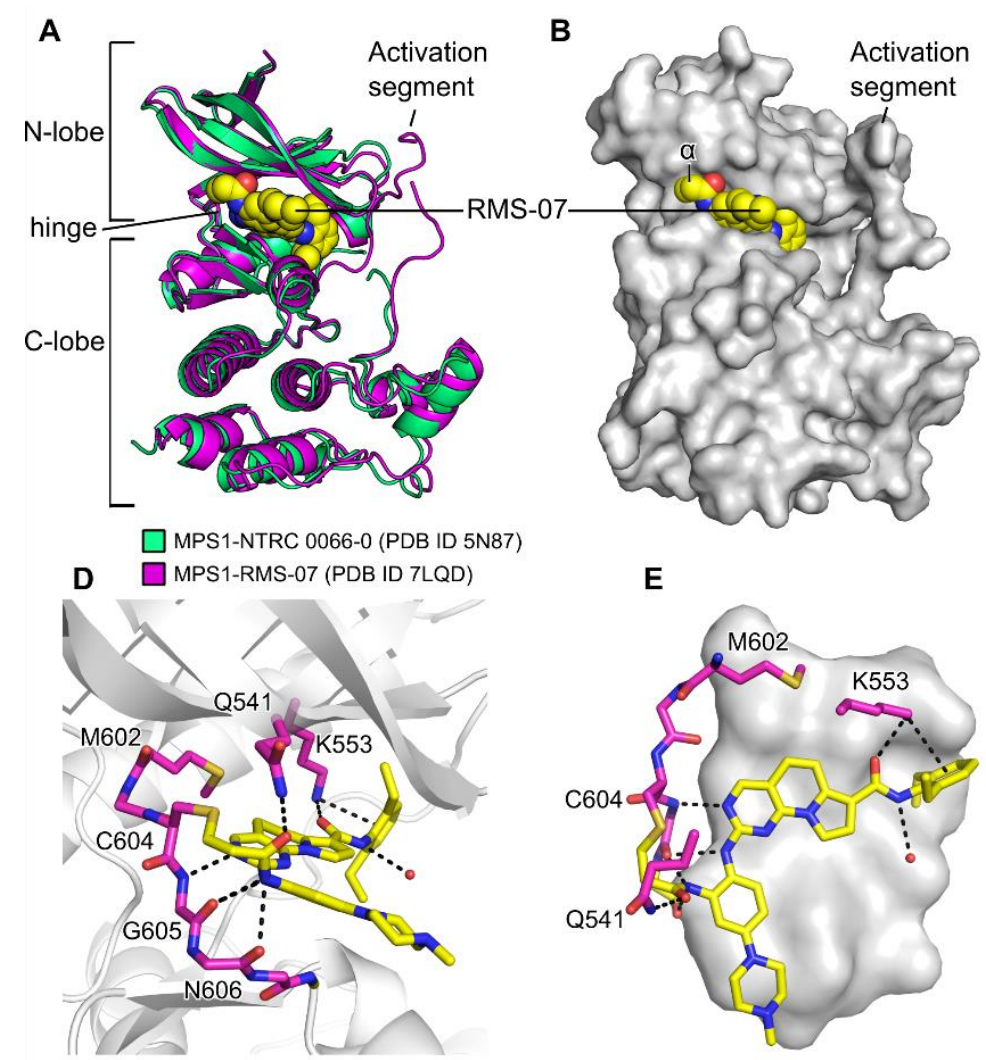

C
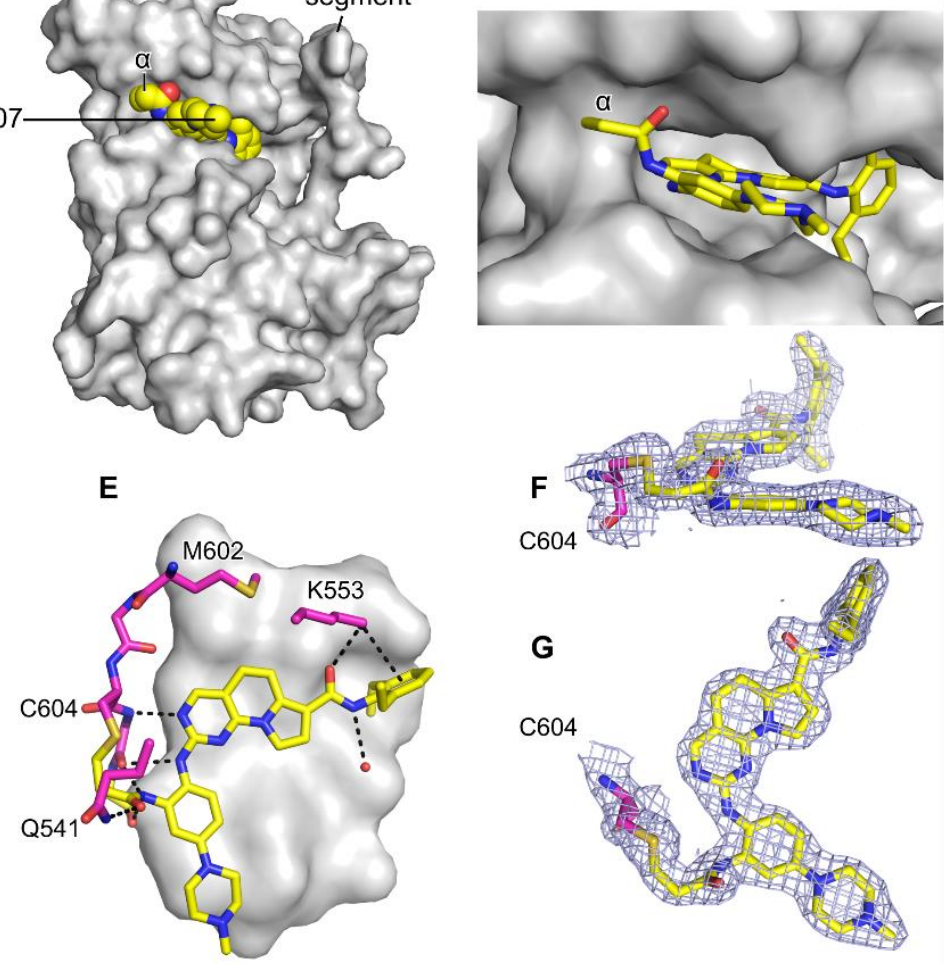

Figure 4 - Structural analysis of the co-crystal structure of RMS-07 bound to the MPS1 kinase domain. A Overall fold of MPS1 (magenta cartoon) bound to RMS-07 (yellow spheres) (PDB code: 7LQD) superimposed to the structure of MPS1 bound to NTRC 0066-0 (compound 8, PDB code: 5 N87, ligand omitted for clarity) ${ }^{26}$. B Surface view of RMS-07 (spheres) bound to MPS1. C Detailed view of RMS-07 (sticks) bound to MPS1 (white molecular surface). The solvent-exposed acrylamide $\alpha$-position is highlighted. D, E - Side (D) and top (E) views of the MPS1 ATP-binding site highlighting the interactions of RMS-07 (sticks) to protein residues (interacting residues and the gatekeeper residue Met602 are shown as sticks) and a crystallographic water (shown as a 
red sphere). Hydrogen bonds and the cation- $\pi$ interaction are shown as black dashed lines. $\mathbf{F}, \mathbf{G}$ - Side (F) and top (G) views for RMS-07 electron density maps (light blue mesh depicts a $2 \mathrm{~F}_{\mathrm{O}}-\mathrm{F}_{\mathrm{C}}$ OMIT map contoured at $1.5 \sigma$ ). MPS1 is shown in the same orientation in panels A to D and F, and in panels $\mathrm{E}$ and $\mathrm{G}$.

In general, presence of suitable moieties at the $\alpha$ - and $\beta$-positions of the acrylamide warhead can modulate reactivity towards thiol groups. For example, a recent analysis of various $\alpha$ - and $\beta$-substituted $N$-phenylacrylamides showed that certain electron-withdrawing groups or dialkyamino methyl substituents at both positions can accelerate covalent bond formation ${ }^{42}$. The co-crystal structure of RMS-07 bound to MPS1 suggested that such moieties might be installed to fine-tune the inactivation kinetics. Nevertheless, to prevent steric clashes, modifications at the $\beta$-position should probably be restricted to small substituents while the acrylamide $\alpha$-position may also accommodate bulkier groups.

The crystal structures of MPS1-KD bound to compound $\mathbf{8}^{26}$ and RMS-07 readily superimposed (root-mean-square deviation (RMSD) of $\sim 0.5 \AA ̊$ over 227 equivalent $C \alpha$ atoms), and the positions of the side chains from the kinases ATP-binding site (defined as those within a $5.0 \AA$ A radius from RMS-07) were mostly conserved in both structures. Notable differences were observed for the position of the catalytic Lys553 residue, which is wrapped by a PEG moiety in the MPS1/8 structure, and that of residue GIn541, which engages the compound via a hydrogen bond in our co-structure (Figure 4D, E). In vicinity of Lys553 and the RMS-07 diethyl phenyl group, we also observed ordered PEG and glycerol molecules from the crystallization and cryoprotection solutions, respectively. Similar solvent molecules were also reported in the available co-crystal structure of 8 bound to MPS1 ${ }^{26}$.

Previous structural analyses of MPS1 bound to different inhibitors identified distinct orientations of the kinase activation segment (residues 667-690 in MPS1) to be important for rationalizing compound potencies ${ }^{26}$. In the MPS1/RMS-07 co-crystal structure, the kinase activation segment adopted an unusual conformation which was not observed in previous ligand-bound or apo MPS1 structures (Figure 4A, B). The activation segment is a conserved structural element of the kinase fold located between two conserved kinase motifs defined by the amino acid triads DFG and APE (PPE in MPS1), and functions as a platform for the kinase peptide substrate. In general, the activation segment is highly dynamic and frequently disordered (and thus missing in electron density maps) even when the kinase is bound to a potent inhibitor. In our structure, the unusual conformation of the MPS1 activation loop is likely to reflect the extensive crystal contacts of this region to symmetry-related MPS1 molecules within the crystal lattice rather than being related to RMS-07 binding (Supplemental Figure S3). 
Selectivity evaluation. The selectivity of inhibitor $\mathbf{8}$ in a panel of 276 human kinases was previously reported ${ }^{36}$. At $100 \mathrm{nM}$, this compound inhibited $99.3 \%$ of MPS1 enzymatic activity and 10 other human kinases were inhibited $\geq 50 \%$ (PLK1, PLK3, PLK4, TNK1, MNK2, TSSK1, NuaK1, AurC, PKD2 and NuaK2) suggesting high intrinsic selectivity of the template ligand chosen for this study. The latter kinase panel also included all four other human kinases having a cysteine residue at the $G K+2$ position, but these were either only marginally inhibited ( 20.8 and $4.9 \%$ inhibition for P70S6K $\beta$ and MAPKAPK2, respectively) or not inhibited at all (FGFR4 and MAPKAPK3 3$)^{36}$.

Here, we used a thermal shift assay (differential scanning fluorimetry, DSF) ${ }^{45}$ to assess the ability of RMS-07 to increase the thermostability of 97 purified human kinases covering all major groups (Supplementary Figure S4) and 3 common off-target bromodomains. This panel included MPS1 and had other 60 proteins in common with the aforementioned study performed by Maia and colleagues ${ }^{36}$. Nevertheless, our panel included only one of the human kinases having a cysteine residue at position $\mathrm{GK}+2$, namely MAPKAPK2, and only one of the proteins shown previously to be inhibited $>50 \%$ by compound 8 , namely PLK4 ${ }^{36}$. In these assays, RMS-07 induced a shift in the mid-point denaturation temperature $\left(\Delta \mathrm{T}_{\mathrm{m}}\right)>3.0^{\circ} \mathrm{C}$ for MPS1 and 9 additional human kinases, including PLK4 which had been previously identified as a potential off-target of inhibitor $\mathbf{8}^{36}$ (Supplementary Table S3). By far the strongest thermal shift was observed for MPS1 $\left(15.8{ }^{\circ} \mathrm{C}\right)$, for which the shift was also significantly higher than the one detected for MPS1/staurosporine $\left(12.4^{\circ} \mathrm{C}\right)$. Our DSF results suggest that RMS-07, as previously observed for compound $\mathbf{8}$, does not have a strong affinity for the kinase domain of MAPKAPK2, despite the presence of a GK+2 cysteine.

To complement our DSF results, we used a commercial radiometric assay to obtain $I C_{50}$ values for RMS-07 on the four other human kinases with an equivalent cysteine placement ${ }^{20}$. The results confirmed that RMS-07 has a high selectivity against all of these enzymes (Table 1). Although additional experiments are needed to fully characterize the kinome-wide selectivity of RMS-07 and potential follow-up compounds, our results from both DSF and enzymatic assays suggested that the addition of the acrylamide warhead to generate RMS-07 did not negatively affect the good selectivity profile observed for compound $\mathbf{8}^{36}$. 
Table 1: IC 50 values of compound RMS-07 against kinases containing an equivalently positioned cysteine residue in the central hinge region (GK+2 position).

\begin{tabular}{ll}
\hline Kinase & $\mathrm{IC}_{50}(\mu \mathrm{M})^{\mathbf{1}}$ \\
\hline FGFR4 & 2.75 \\
MAPKAPK2 & $>5$ \\
MAPKAPK3 & $>5$ \\
p70S6K $\beta$ & 1.65 \\
\hline
\end{tabular}

${ }^{1}$ ATP concentration $=10 \mu \mathrm{M}$; Data commercially determined at ReactionBiology Corp. using the Hotspot ${ }^{\mathrm{TM}}$ platform ${ }^{46}$.

Glutathione stability and in vitro metabolism. To determine the intrinsic reactivity toward thiols under physiological conditions, we evaluated the stability of RMS-07 against excess glutathione as a physiologically relevant nucleophile. Under the assayed conditions (5 mM GSH at $\mathrm{pH}$ 7.4), RMS-07 showed a much longer half-life compared to the approved drug Afatinib $\left(\mathrm{t}_{1 / 2}\right.$ : $84.5 \mathrm{~h}$ and $4.98 \mathrm{~h}$, respectively; see the Supplementary Figures S5 and S6) confirming low intrinsic reactivity. Additionally, we estimated metabolic stability by incubation with mouse liver microsomes (MLM). Microsomal stability was moderated with approximately half of the compound being metabolized within one hour ( $\mathrm{t}_{1 / 2}: \sim 60 \mathrm{~min}$, Figure 6$)$ comparing favorably to the value reported for prototype $8\left(t_{1 / 2}: 13 \mathrm{~min}\right)^{36}$. The major metabolite featured a $\mathrm{m} / \mathrm{z}$ of 621 (Figure 6), a mass consistent with hydroxylation or $\mathrm{N}$-oxidation as the predominant metabolic transformation. However, further studies will be required to specify and mitigate the metabolic hotspot.

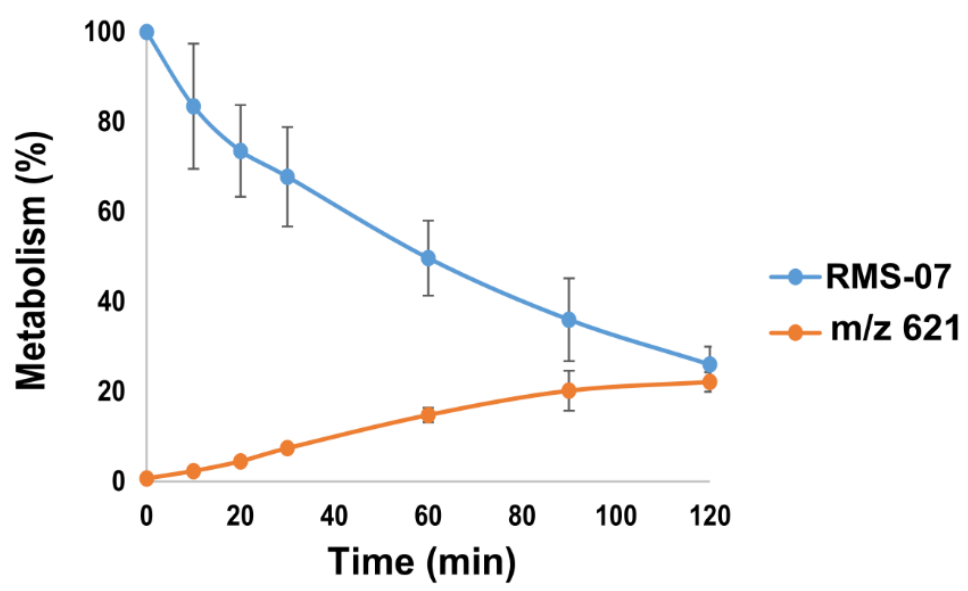

Figure 6 - In vitro metabolism of compound RMS-07 in mouse liver microsomes. The graphic shows the decrease of analyte concentration ( \pm s.d.) and formation of the major metabolite over 120 minutes. 


\section{Conclusions}

By employing a structure-based approach, we were able to design and synthetize the first-inclass covalent MPS1 inhibitor RMS-07 (9). Design started from structural data of reversible inhibitor NTRC 0066-0 (8) from which the ortho-methoxy group was replaced by a classical acrylamide warhead to irreversibly hit the proximal Cys604 in the middle hinge region. We developed a convenient synthetic access to this compound enabling future structure-activity relationship (SAR) studies. The compound shows high potency with its covalent mode-of-action being confirmed by enzymatic assays and liquid chromatography-mass spectrometry. We gained detailed insight into the binding mode of the title compound by solving the $\mathrm{X}$-ray crystal structure of the complex MPS1/RMS-07, which further validated the covalent interaction. Moreover, it is worth mentioning that preliminary NanoBRET ${ }^{\mathrm{TM}}$ experiments (data not shown) corroborated cellular target engagement and a prolonged resident-time.

RMS-07 showed high selectivity over other kinases sharing a cysteine at the same position as well as a good selectivity profile in a DSF-based screening panel comprising almost 100 kinases. Additionally, we observed high stability against glutathione and only moderate susceptibility to in vitro metabolism.

This work showcases that establishing a covalent interaction with MPS1-Cys604 can be a fruitful strategy to obtain potent and selective compounds achieving durable target engagement. Such strategy may help to clarify the role of residence time for MPS1 inhibitor efficacy and might be particularly useful in a clinical setting, where it may further decouple the pharmacological effect from pharmacokinetics (PK). To become useful for such applications, however, PK and covalent binding kinetics will require further optimization. Therefore, future efforts will aim at the investigation of structure-activity relationships to fine-tune affinity, inactivation kinetics and metabolic stability. Taken together, this study represents an important first step towards highly specific and efficacious covalent MPS1 inhibitors to be used as in vitro or in vivo chemical probes or in future drug development efforts. 


\section{Experimental Section}

\section{Chemistry}

All starting materials and reagents were of commercial quality and were used without further purification. Thin layer chromatography (TLC) was carried out on Merck 60 F254 silica plates (Merck KGaA, Darmstadt, Germany) and spots were visualized under UV light (254 nm and 366 $\mathrm{nm}$ ) or developed with an appropriate staining reagent. Preparative column chromatography was carried out with an Interchim PuriFlash 430 or PuriFlash XS420 system (Interchim S.A., Montlucon, Allier, France) on normal phase silica gel (Grace Davison Davisil LC60A 20-45 micron; W.R. Grace and Company, Columbia, MD, USA or Merck Geduran Si60 63-200-micron silica; Merck KGaA, Darmstadt, DE).

Nuclear magnetic resonance (NMR) spectra were recorded on Bruker Avance 400 instruments (Bruker Corporation, Billerica, MA, USA). The samples were dissolved in deuterated solvents and chemical shifts are given in ppm in relation to tetramethylsilane (TMS). Spectra were calibrated using the residual proton or carbon peaks of the used solvent. Mass spectrometry (MS) was carried out with an Advion TLC-MS interface (Advion, Ithaca, NY, USA) with electron spray ionization (ESI) in positive and/or negative mode. Instrument settings were as follows: ESI voltage $3.50 \mathrm{kV}$, capillary voltage $187 \mathrm{~V}$, source voltage $44 \mathrm{~V}$, capillary temperature $250{ }^{\circ} \mathrm{C}$, desolvation gas temperature $250{ }^{\circ} \mathrm{C}$, gas flow $5 \mathrm{~L} / \mathrm{min}$ nitrogen. High-resolution mass spectrometry (HRMS) for the final compound was measured by the mass spectrometry department, Institute of Organic Chemistry, Eberhard Karls University Tuebingen on a Bruker maXis 4G ESI-TOF. The instrument was run in ESI+ Mode, settings were as follows: nebulizer gas $1.2 \mathrm{bar}$, gas flow, $6.0 \mathrm{~L} / \mathrm{min}$, source temperature $200^{\circ} \mathrm{C}$, capillary voltage $+4500 \mathrm{~V}$, end plate offset $-500 \mathrm{~V} . \mathrm{m} / \mathrm{z}$ range from 80 to $1000 \mathrm{~m} / \mathrm{z}$.

Purity of the final compound was determined via high performance liquid chromatography (HPLC) using an Agilent 1100 Series LC system (Agilent Technologies, Santa Clara, CA, USA) with a Phenomenex Kinetex C8 100A column $(150 \times 4.6$ mm, $2.6 \mu \mathrm{m})$ (Phenomenex Inc. Torrance, CA, USA) and detection was performed with a UV DAD at $254 \mathrm{~nm}$ and $230 \mathrm{~nm}$ wavelength. Elution was carried out with the following gradients: $0.01 \mathrm{M} \mathrm{KH}_{2} \mathrm{PO}_{4}, \mathrm{pH} 2.32$ (solvent A), $\mathrm{MeOH}$ (solvent B). Method A = 0 min: $40 \%$ B / 60\% A, 9 min: 95\% B / 5\% A, 10 min: 95\% B / 5\% A, 11 min: 40\% B / $60 \%$ A, 16 min: 40\% B / 60\% A, flow 0.5 mL/min. Method B = 0 min: 40\% B / 60\% A, 15 min: 85\% B / 15\% A, 20 min: 85\% B / 15\% A, 22 min: 40\% B / 60 \% A, 28 min: 40\% B / 60 \% A, flow 0.5 $\mathrm{mL} / \mathrm{min}$. The final compound showed a purity above $95 \%$ according to the peak areas at the two different wavelengths. 
Di-tert-butyl 4-bromo-2-nitrophenyliminodicarbonate (11): To a solution of 4-bromo-2nitroaniline (10, $2.00 \mathrm{~g}, 9.22 \mathrm{mmol}, 1$ eq.) in THF (30 mL) were added $\mathrm{Boc}_{2} \mathrm{O}(4.12 \mathrm{~g}, 18.9 \mathrm{mmol}$, 2.05 eq.) and DMAP (10 mol\%). The reaction was stirred overnight at $65^{\circ} \mathrm{C}$. After cooling to room temperature, water $(5 \mathrm{~mL})$ was added, and the mixture was stirred for 30 minutes. Subsequently, extraction was performed three times using $\mathrm{AcOEt}$ and $\mathrm{NaHCO}_{3}$ (saturated aqueous solution). The organic phases were combined, washed with brine, dried over $\mathrm{Na}_{2} \mathrm{SO}_{4}$ and concentrated under reduced pressure. The desired intermediate $\mathbf{1 1}$ was obtained as a yellowish solid in $93 \%$ yield $(3.56 \mathrm{~g})$ without further purification. ${ }^{1} \mathrm{H} \mathrm{NMR}\left(400 \mathrm{MHz}, \mathrm{CDCl}_{3}\right) \delta$ $8.20(\mathrm{~d}, J=2.3 \mathrm{~Hz}, 1 \mathrm{H}), 7.75(\mathrm{dd}, J=8.4,2.3 \mathrm{~Hz}, 1 \mathrm{H}), 7.21(\mathrm{~d}, J=8.4 \mathrm{~Hz}, 1 \mathrm{H}), 1.40(\mathrm{~s}, 18 \mathrm{H}) .{ }^{13} \mathrm{C}$ NMR $\left(101 \mathrm{MHz}, \mathrm{CDCl}_{3}\right) \delta 150.0,146.1,136.8,132.7,132.5,128.2,121.9,84.3,27.9$. TLC-MS (ESI) $\mathrm{m} / \mathrm{z}: 439.2[\mathrm{M}+\mathrm{Na}]^{+}$. HPLC $\mathrm{t}_{\text {ret }}: 12.22 \mathrm{~min}(\operatorname{Method} \mathrm{A})$.

4-(4-Methylpiperazin-1-yl)-2-nitroaniline (12): A Schlenk flask equipped with a magnetic stir bar was charged with $\mathrm{Cs}_{2} \mathrm{CO}_{3}$ (2.63 g, 1.3 eq.), SPhosPdG3 (5 mol\%), $\mathrm{N}$-methylpiperazine (1.45 mL, 2.1 eq.), intermediate 11 (2.60 g, $6.22 \mathrm{mmol}, 1.0$ eq.) and dry/degassed 1,4-dioxane (16.3 mL). The reaction mixture was stirred under argon atmosphere for 12 hours at $105^{\circ} \mathrm{C}$. After cooling to room temperature, the material was extracted three times with $\mathrm{AcOEt}$ and $\mathrm{NaHCO}_{3}$ (saturated aqueous solution). The organic phases were combined, washed with brine, dried over $\mathrm{Na}_{2} \mathrm{SO}_{4}$ and concentrated under reduced pressure. The product was purified by flash chromatography (in a gradient system using: $0-15 \%$ methanol in DCM plus $1 \%$ of $\mathrm{NH}_{3}$ ). To remove the Boc protecting group, the isolated material was dissolved in DCM $(60.0 \mathrm{~mL})$ and TFA $(20.0 \mathrm{~mL})$ was added. The mixture was stirred for 3 hours at room temperature. After that, the mixture was concentrated under reduced pressure, and the resulting residue was taken up in DCM and extracted three times with $\mathrm{NaHCO}_{3}$ (saturated aqueous solution). The organic phases were combined, dried over $\mathrm{Na}_{2} \mathrm{SO}_{4}$ and concentrated under reduced pressure again. The product was purified by flash chromatography (in a gradient system using: $0-15 \%$ methanol in DCM plus $1 \%$ of $\mathrm{NH}_{3}$ ). The desired intermediate 12 was obtained as a reddish solid in $64 \%$ yield (0.94 g). ${ }^{1} \mathrm{H}$ NMR (400 MHz, $\left.\mathrm{CDCl}_{3}\right) \delta 7.55(\mathrm{~d}, J=2.8 \mathrm{~Hz}, 1 \mathrm{H}), 7.16(\mathrm{dd}, J=9.1,2.8 \mathrm{~Hz}, 1 \mathrm{H}), 6.76$ $(\mathrm{d}, J=9.1 \mathrm{~Hz}, 1 \mathrm{H}), 5.85(\mathrm{~s}, 2 \mathrm{H}), 3.13-3.07(\mathrm{~m}, 4 \mathrm{H}), 2.60-2.56(\mathrm{~m}, 4 \mathrm{H}), 2.35(\mathrm{~s}, 3 \mathrm{H}) .{ }^{13} \mathrm{C} N M R$ $\left(101 \mathrm{MHz}, \mathrm{CDCl}_{3}\right) \delta 142.9,139.6,132.2,128.3,119.8,111.0,55.1,50.2,46.2$. TLC-MS (ESI) $\mathrm{m} / \mathrm{z}$ : $237.2[\mathrm{M}+\mathrm{H}]^{+}$. HPLC $\mathrm{t}_{\text {ret }}: 3.25 \min ($ Method $A)$.

Intermediate 13 was synthesized according to literature procedures described in Refs ${ }^{34,35}$. 2-((4-(4-Methylpiperazin-1-yl)-2-nitrophenyl)amino)-5,6-dihydropyrimido[4,5-e]indolizine-7carboxylic acid hydrochloride (14): A Schlenk flask equipped with a magnetic stir bar was charged with $\mathrm{Cs}_{2} \mathrm{CO}_{3}(0.97 \mathrm{~g}, 2.5 \mathrm{eq})$, BrettPhosPdG3 (5 mol\%), intermediate 12 (0.30 g, 1.05 
eq.), intermediate 13 (0.33 g, $1.19 \mathrm{mmol}, 1$ eq.) and a dry/degassed mixture of 1,4-dioxane:t$\mathrm{BuOH}(4: 1,9.0 \mathrm{~mL})$ was added as the solvent system. The reaction mixture was stirred under argon atmosphere for 7 hours at $110^{\circ} \mathrm{C}$. After cooling to room temperature, the crude material was loaded on celite and directly purified by flash chromatography (in a gradient system using: 0-10\% methanol in DCM). For subsequent ester cleavage, the isolated material was added to a solution of $\mathrm{LiOH} \cdot \mathrm{H}_{2} \mathrm{O}\left(0.18 \mathrm{~g}\right.$, 5 eq.) in THF $(8.2 \mathrm{~mL}), \mathrm{H}_{2} \mathrm{O}(4.1 \mathrm{~mL}), \mathrm{MeOH}(4.1 \mathrm{~mL})$ and stirred for 12 hours at $50{ }^{\circ} \mathrm{C}$. After cooling to room temperature, the medium was acidified using $8.0 \mathrm{~mL}$ of $\mathrm{HCl}(2 \mathrm{M}$ aq.) and concentrated under reduced pressure. The product was purified by reverse phase flash chromatography ( $\mathrm{C} 18$ column with a gradient system using: $80 \% \mathrm{H}_{2} \mathrm{O} / 20 \% \mathrm{MeOH}$ $\rightarrow 90 \% \mathrm{MeOH} / 10 \% \mathrm{H}_{2} \mathrm{O}$, plus $\left.\mathrm{HCl}(0.005 \mathrm{M})\right)$. The desired intermediate 14 was obtained as a reddish solid in 67\% yield (0.39 g). ${ }^{1} \mathrm{H}$ NMR (400 MHz, DMSO) $\delta 11.26(\mathrm{~s}, 1 \mathrm{H}), 9.90(\mathrm{~s}, 1 \mathrm{H}), 8.35$ (s, 1H), $7.72(\mathrm{~d}, J=9.1 \mathrm{~Hz}, 1 \mathrm{H}), 7.56(\mathrm{~d}, J=2.8 \mathrm{~Hz}, 1 \mathrm{H}), 7.43(\mathrm{dd}, J=9.1,2.8 \mathrm{~Hz}, 1 \mathrm{H}), 7.32(\mathrm{~d}, J=$ $3.3 \mathrm{~Hz}, 1 \mathrm{H}), 6.58(\mathrm{~d}, J=3.3 \mathrm{~Hz}, 1 \mathrm{H}), 4.83(\mathrm{bs}, 1 \mathrm{H}), 3.92(\mathrm{~d}, J=12.3 \mathrm{~Hz}, 2 \mathrm{H}), 3.49(\mathrm{~d}, J=10.9 \mathrm{~Hz}$, 2H), $3.25-3.11(\mathrm{~m}, 6 \mathrm{H}), 2.83-2.77(\mathrm{~m}, 5 \mathrm{H}) .{ }^{13} \mathrm{C}$ NMR (101 MHz, DMSO) $\delta 165.3,157.9,156.7$, $153.3,145.7,142.3,136.4,126.2,125.3,121.9,115.3,114.7,112.4,110.9,109.7,51.7,45.2$, 41.8, 20.4, 20.3. MS (ESI) $m / z: 450.31[\mathrm{M}+\mathrm{H}]^{+}$. HPLC tret: 8.05 min (Method A).

\section{N-(2,6-Diethylphenyl)-2-((4-(4-methylpiperazin-1-yl)-2-nitrophenyl)amino)-5,6-}

dihydropyrimido[4,5-e]indolizine-7-carboxamide (15): The intermediate 14 (0.15 g, $0.31 \mathrm{mmol}$, 1.0 eq.) was mixed with $\mathrm{DCM}(7.5 \mathrm{~mL})$ and $\mathrm{SOCl}_{2}(0.45 \mathrm{~mL}, 20$ eq. $)$ was added at $0^{\circ} \mathrm{C}$. The reaction was kept stirring at room temperature for 48 hours. The material was subsequently concentrated under reduced pressure and added ACN (60 mL), DMAP (0.037 g, 1.0 eq.), and 2,6diethylaniline (20 eq.). The mixture was stirred for 72 hours at $65^{\circ} \mathrm{C}$. After cooling down to room temperature, the crude product was concentrated under reduced pressure and purified by flash chromatography (in a gradient system using: $0-10 \%$ methanol in DCM plus $1 \%$ of $\mathrm{NH}_{3}$ ). The desired intermediate 15 was obtained as a reddish solid in $86 \%$ yield $(0.15 \mathrm{~g}) .{ }^{1} \mathrm{H} \mathrm{NMR}$ (400 MHz, DMSO) $\delta 9.73(s, 1 \mathrm{H}), 9.21(\mathrm{~s}, 1 \mathrm{H}), 8.31(\mathrm{~s}, 1 \mathrm{H}), 7.76(\mathrm{~d}, J=8.9 \mathrm{~Hz}, 1 \mathrm{H}), 7.48(\mathrm{~d}, J=2.7 \mathrm{~Hz}, 1 \mathrm{H})$, $7.42-7.38(\mathrm{~m}, 2 \mathrm{H}), 7.21(\mathrm{dd}, J=8.2,6.8 \mathrm{~Hz}, 1 \mathrm{H}), 7.13(\mathrm{~d}, J=7.4 \mathrm{~Hz}, 2 \mathrm{H}), 6.99(\mathrm{~d}, J=3.4 \mathrm{~Hz}, 1 \mathrm{H})$, $3.30-3.23(\mathrm{~m}, 6 \mathrm{H}), 2.79(\mathrm{t}, J=7.3 \mathrm{~Hz}, 2 \mathrm{H}), 2.70(\mathrm{~s}, 3 \mathrm{H}), 2.58-2.51(\mathrm{~m}, 5 \mathrm{H}), 2.39(\mathrm{~s}, 3 \mathrm{H}), 1.11(\mathrm{t}$, $J=7.5 \mathrm{~Hz}, 6 \mathrm{H}) .{ }^{13} \mathrm{C}$ NMR (101 MHz, DMSO) $\delta$ 162.9, 158.3, 157.4, 153.1, 141.8, 141.6, 134.5, 134.2, 127.0, 125.7, 125.6, 125.4, 121.7, 117.0, 114.9, 110.5, 110.0, 109.7, 53.6, 47.1, 44.6, 24.4, 20.4, 20.3, 14.3. MS (ESI) $\mathrm{m} / \mathrm{z}: 581.44\left[\mathrm{M}+\mathrm{H}^{+}\right.$. HPLC tret: $10.16 \mathrm{~min}$ (Method A).

\section{2-((2-Amino-4-(4-methylpiperazin-1-yl)phenyl)amino)-N-(2,6-diethylphenyl)-5,6-}

dihydropyrimido[4,5-e]indolizine-7-carboxamide (16): The intermediate 15 (40.0 mg, 0.07 mmol, 1.0 eq.) was combined with $\mathrm{SnCl}_{2}$ (55.0 mg, 4.0 eq.) and a mixture of EtOH:THF (2:1, 9.5 
$\mathrm{mL}$ ) was added as the solvent system. The reaction was stirred for 2.5 hours at $65^{\circ} \mathrm{C}$. The mixture was concentrated under reduced pressure and the resulting residue was extracted three times using $\mathrm{AcOEt}_{\text {and }} \mathrm{NaHCO}_{3}$ (saturated aqueous solution). The organic layers were combined, dried over $\mathrm{Na}_{2} \mathrm{SO}_{4}$ and concentrated under reduced pressure yielding the intermediate 16 , without further purification, as a pale yellow solid in $95 \%$ yield. ${ }^{1} \mathrm{H} N M R\left(400 \mathrm{MHz}, \mathrm{CDCl}_{3}\right) \delta 8.17(\mathrm{~s}, 1 \mathrm{H})$, $7.52(\mathrm{~d}, J=3.3 \mathrm{~Hz}, 1 \mathrm{H}), 7.24-7.21(\mathrm{~m}, 1 \mathrm{H}), 7.19-7.13(\mathrm{~m}, 3 \mathrm{H}), 7.05(\mathrm{~s}, 1 \mathrm{H}), 6.58(\mathrm{~s}, 1 \mathrm{H}), 6.52$ $(\mathrm{d}, J=3.4 \mathrm{~Hz}, 1 \mathrm{H}), 6.44-6.38(\mathrm{~m}, 2 \mathrm{H}), 3.46(\mathrm{~s}, 1 \mathrm{H}), 3.38(\mathrm{t}, J=7.3 \mathrm{~Hz}, 2 \mathrm{H}), 3.22-3.17(\mathrm{~m}, 4 \mathrm{H})$, $2.79(\mathrm{t}, J=7.3 \mathrm{~Hz}, 2 \mathrm{H}), 2.65(\mathrm{q}, J=7.5 \mathrm{~Hz}, 5 \mathrm{H}), 2.60-2.55(\mathrm{~m}, 4 \mathrm{H}), 2.35(\mathrm{~s}, 3 \mathrm{H}), 1.20(\mathrm{t}, J=7.5$ $\mathrm{Hz}, 6 \mathrm{H}) .{ }^{13} \mathrm{C}$ NMR $\left(101 \mathrm{MHz}, \mathrm{CDCl}_{3}\right) \delta 163.7,161.1,157.8,154.3,150.8,143.1,141.8,135.6$, 132.9, 127.9, 127.6, 126.4, 117.7, 116.8, 116.1, 109.1, 108.8, 107.5, 104.3, 55.3, 49.3, 46.3, 29.8, $25.1,21.4,14.5$

\section{2-((2-Acrylamido-4-(4-methylpiperazin-1-yl)phenyl)amino)-N-(2,6-diethylphenyl)-5,6-}

dihydropyrimido[4,5-e]indolizine-7-carboxamide (9, RMS-07): The aniline intermediate 16 (15.0 mg, $27.0 \mu \mathrm{mol}, 1.0$ eq.) and DIPEA (7.05 $\mu \mathrm{L}, 1.5$ eq.) were dissolved in dry DMF (2.0 mL) and kept stirring at $-10{ }^{\circ} \mathrm{C}$ under argon atmosphere. Then, acryloyl chloride ( $2.62 \mu \mathrm{L}, 1.2$ eq.) freshly dissolved in dry DMF $(0.5 \mathrm{~mL})$ was added dropwise. The mixture was stirred for 3 hours and after warming up to room temperature, the crude product was extracted three times using AcOEt $/ \mathrm{H}_{2} \mathrm{O}$, the combined organic layers were dried over $\mathrm{Na}_{2} \mathrm{SO}_{4}$ and concentrated under reduced pressure. The product was purified by flash chromatography column (in a gradient system using: 0-20\% methanol in DCM). The desired final product 9 (RMS-07) was obtained as a white solid in $66 \%$ yield $(10.7 \mathrm{mg}) .{ }^{1} \mathrm{H}$ NMR $\left(400 \mathrm{MHz}, \mathrm{CDCl}_{3}\right) \delta 8.37(\mathrm{~s}, 1 \mathrm{H}), 8.17(\mathrm{~s}, 1 \mathrm{H}), 7.67(\mathrm{~s}$, $1 \mathrm{H}), 7.49(\mathrm{~d}, J=3.3 \mathrm{~Hz}, 1 \mathrm{H}), 7.29-7.22(\mathrm{~m}, 2 \mathrm{H}), 7.14(\mathrm{~d}, J=7.6 \mathrm{~Hz}, 2 \mathrm{H}), 7.07(\mathrm{~s}, 1 \mathrm{H}), 6.99(\mathrm{~s}, 1 \mathrm{H})$, $6.74(\mathrm{~d}, J=7.0 \mathrm{~Hz}, 1 \mathrm{H}), 6.53(\mathrm{~d}, J=3.4 \mathrm{~Hz}, 1 \mathrm{H}), 6.37(\mathrm{~d}, J=16.8 \mathrm{~Hz}, 1 \mathrm{H}), 6.17(\mathrm{dd}, J=16.8,10.2$ $\mathrm{Hz}, 1 \mathrm{H}), 5.69(\mathrm{~d}, J=9.4 \mathrm{~Hz}, 1 \mathrm{H}), 3.39(\mathrm{t}, J=7.3 \mathrm{~Hz}, 2 \mathrm{H}), 3.30-3.23(\mathrm{~m}, 4 \mathrm{H}), 2.81(\mathrm{t}, J=7.3 \mathrm{~Hz}$, 2H), $2.66-2.60(\mathrm{~m}, 8 \mathrm{H}), 2.38(\mathrm{~s}, 3 \mathrm{H}), 1.20(\mathrm{t}, J=7.6 \mathrm{~Hz}, 6 \mathrm{H}) .{ }^{13} \mathrm{C} \mathrm{NMR}\left(101 \mathrm{MHz}, \mathrm{CDCl}_{3}\right) \delta 163.9$, $163.7,160.8,157.4,154.4,149.8,141.8,135.5,133.7,132.8,131.6,128.0,127.6,126.7,126.4$, 122.2 , 117.1, 116.2, 112.9, 111.0, 109.6, 109.4, 55.1, 48.9, 46.0, 29.8, 25.1, 21.4, 14.5. HRMS ESITOF: $\mathrm{m} / z$ calcd for $\mathrm{C}_{35} \mathrm{H}_{41} \mathrm{~N}_{8} \mathrm{O}_{2}\left[\mathrm{M}+\mathrm{H}^{+}\right.$: 605.33470. Found: 605.33452. HPLC $\mathrm{t}_{\text {ret: }} 12.51 \mathrm{~min}$ (Method B).

\section{Production of recombinant MPS1 Kinase Domain (MPS1-KD)}

MPS1 kinase domain (MPS1-KD; residues Ser519 to Glu808) in pNIC28-Bsa4 was transformed into chemically competent Escherichia coli BL21(DE3)-R3 cells that co-express $\lambda$-phosphatase and three rare tRNAs (plasmid pACYC-LIC+) 47,33 . Colonies were used to inoculate $50 \mathrm{~mL}$ of LB 
media supplemented with $5 \mathrm{mM}$ betaine, $50 \mu \mathrm{g} / \mathrm{mL}$ kanamycin and $35 \mu \mathrm{g} / \mathrm{mL}$ chloramphenicol which was left shaking (150 r.p.m.) at $37^{\circ} \mathrm{C}$ overnight. This culture was used to inoculate $1.5 \mathrm{~L}$ of Terrific Broth containing $50 \mu \mathrm{g} / \mathrm{mL}$ kanamycin at $37^{\circ} \mathrm{C}$ until the $\mathrm{OD}_{600}$ reached 3 . The culture was cooled to $18^{\circ} \mathrm{C}, 0.2 \mathrm{mM}$ of isopropyl $\beta$-D-1-thiogalactopyranoside (IPTG) was added, and left overnight. Cells were collected by centrifugation for $15 \mathrm{~min}$ at $7,500 \times \mathrm{g}$ at room temperature. The cell pellet was weighed and suspended in (1:1 wet weight in grams to $\mathrm{mL}$ ) $2 x$ binding buffer ( $1 x$ binding buffer was $50 \mathrm{mM}$ HEPES $\mathrm{pH}$ 7.5, $500 \mathrm{mM} \mathrm{NaCl}, 10 \%$ glycerol, $10 \mathrm{mM}$ imidazole, $1 \mathrm{mM}$ tris(2-carboxyethyl)phosphine (TCEP) with protease inhibitors set II (Calbiochem) at 1:200 ratio) and frozen at $-80^{\circ} \mathrm{C}$ until use. The cell pellet was thawed and sonicated on ice. Polyethylene imine $(\mathrm{pH} 7.5)$ was added to the lysate to a final concentration of $0.15 \%(\mathrm{w} / \mathrm{v})$ and the sample was centrifuged at $53,000 \times \mathrm{g}$ for $45 \mathrm{~min}$ at $4{ }^{\circ} \mathrm{C}$. The supernatant was loaded onto an immobilized metal affinity chromatography (IMAC) column ( $5 \mathrm{~mL}$ HisTrap FF Crude) and washed in binding buffer containing $30 \mathrm{mM}$ imidazole. The protein was eluted with elution buffer (binding buffer with $300 \mathrm{mM}$ imidazole). Eluted MPS1-KD was further purified by gel filtration (Superdex 200 16/60, GE Healthcare). Protein in gel filtration buffer (20 mM HEPES, $500 \mathrm{mM} \mathrm{NaCl}, 1 \mathrm{mM}$ TCEP, $5 \%$ [v/v] glycerol) was concentrated to $10 \mathrm{mg} / \mathrm{mL}$ (measured by UV absorbance with a NanoDrop spectrophotometer - Thermo Scientific; using the protein calculated molecular weight and extinction coefficient) using $10 \mathrm{kDa}$ molecular weight cut-off centrifugal concentrators (Millipore) at $4{ }^{\circ} \mathrm{C}$. LC-MS was used to verify the protein intact mass. The N-terminal affinity tag introduced during cloning of MPS1 kinase domain into pNIC28-Bsa4 was not removed. Purified protein was aliquoted, flash-frozen in a liquid nitrogen bath and stored at $-80^{\circ} \mathrm{C}$ until use. Typical results for protein purification can be seen in Supplementary Figure S2.

\section{Enzyme inhibition assays}

For enzyme inhibition assays, we used the full-length (residues Met1-Lys857) recombinant MPS1 fused to GST (N-terminal) from Carna Biosciences (cat. \#05-169). MPS1-mediated phosphorylation of peptide Histone H3-ARIKQTARKSTG (underline indicates the phosphorylation site - Perkin Elmer cat. \#TRF0125) was monitored using Perkin Elmer's LANCE Ultra assay kit. Assay development included establishing reaction parameters (optimal enzyme concentration, $K_{\mathrm{M}}$ ATP determination and optimal reaction times). Typical assay development results can be seen in Supplementary Figure S1. 
For $\mathrm{IC}_{50}$ measurement, compound stocks (in $100 \%$ DMSO) were serially diluted in $100 \%$ DMSO (14-point, 3-fold serial dilution and a highest final assay concentration of $20 \mu \mathrm{M}$ ) prior to transfer $(100 \mathrm{~nL})$ to a white, low volume 384-round bottom plate containing $5 \mu \mathrm{L}$ MPS1 (5 nM final assay concentration in kinase buffer) using an automated liquid transferring system (CYBIO FeliX ${ }^{\circledR}$, Analytik Jena, Jena, Germany). Vehicle (DMSO) or $20 \mu \mathrm{M}$ staurosporine were used as controls for 100 and $0 \%$ enzyme activity, respectively. The reaction was started immediately by the addition of $5 \mu \mathrm{L}$ of a mixture containing $288 \mu \mathrm{M}$ ATP and $100 \mathrm{nM}$ Histone-H3. Final assay concentrations were: 2.5 nM MPS1, 144 $\mu \mathrm{M}$ ATP, and 50 nM Histone-H3 peptide. Enzyme and substrates were prepared in enzyme reaction buffer ( $20 \mathrm{mM}$ Hepes, $\mathrm{pH}$ 7.5, $100 \mathrm{mM} \mathrm{NaCl}, 5$ $\mathrm{mM} \mathrm{MgCl}, 0.01 \%$ Tween 20). The reaction was allowed to process for $1 \mathrm{~h}$ at $28^{\circ} \mathrm{C}$ prior to being stopped by the addition of $5 \mu \mathrm{L}$ of $24 \mathrm{mM}$ EDTA diluted in LANCE Detection buffer (Perkin Elmer) followed by the addition of $5 \mu \mathrm{L}$ of a solution containing $8 \mathrm{nM}$ of antibody anti-histone H3-Thr3 (Perkin Elmer, cat. \#TRF0211). Final concentrations for EDTA and antibody were 6 and $2 \mathrm{nM}$, respectively. The plate was incubated at room temperature for one hour. The TR-FRET signal was measured using ClarioStar microplate reader (BMG Labtech) previously set up to $340 \mathrm{~nm}$ excitation and $665 \mathrm{~nm}$ emission wavelengths, $50 \mu$ s delay time, 100 flashes, and $100 \mu \mathrm{s}$ integration time. To determine compound potency $\left(\mathrm{IC}_{50}\right)$, raw fluorescence signal was plotted as a function of test compound concentration, and the data were fitted to the sigmoidal doseresponse (variable slope) equation [1] available in GraphPad Prism:

$$
\text { Raw fluorescence signal }=\text { Plateau }_{\text {bottom }}+\frac{\text { Plateau }_{\text {top }}-\text { Plateau }_{\text {bottom }}}{1+10^{\left(\log \mathrm{IC}_{50}-\mathrm{x}\right) \cdot \text { Hill }}}
$$

where Hill $=$ Hill slope describing the steepness of the curve and $x=$ test compound concentration.

We derived $K_{1}$ and $k_{\text {inact }}$ directly from $\mathrm{IC}_{50}$ values obtained following increasing incubation times of full-length MPS1 with RMS-07 prior to the start of the reaction by addition of ATP following the procedure described by Krippendorff ${ }^{38}$ and colleagues, according to equation [2]:

$$
\mathrm{IC}_{50}(\mathrm{t})=\mathrm{K}_{\mathrm{I}}\left(1+\frac{\mathrm{S}}{\mathrm{K}_{\mathrm{M}, \mathrm{ATP}}}\right) \cdot\left(\frac{2-2 \mathrm{e}^{-\eta_{\mathrm{IC}} \mathrm{C}_{50} \cdot \mathrm{k}_{\text {inact }} \cdot \mathrm{t}}}{\eta_{\mathrm{IC}_{50}} \cdot \mathrm{k}_{\text {inact }} \cdot \mathrm{t}}-1\right)
$$

where $\eta_{1150}$ is defined by equation [3]:

$$
\eta_{I_{50}}=\frac{I_{50}(t)}{K_{I}\left(1+\frac{S}{K_{M, A T P}}\right)+I_{50}(t)}
$$


Evaluation of the RMS-07 potency over time was performed upon different TTK incubation times with RMS-07 before starting the reaction. Firstly, TTK was diluted to $40 \mathrm{nM}$ in kinase buffer

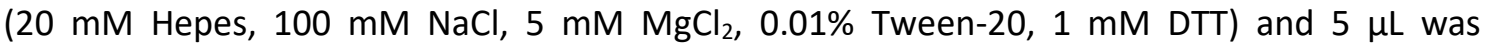
transferred to a white, low volume 384-round bottom plate. RMS-07 was serially diluted from $10 \mathrm{mM}$ in DMSO, for 15 points and 3-fold dilution in each passage. Afterwards, $100 \mathrm{~nL}$ of diluted RMS-07 was transferred to four different plates into wells containing $5 \mu \mathrm{L}$ of $40 \mathrm{nM}$ TTK using an automated liquid transferring system (CYBIO FeliX ${ }^{\circledR}$, Analytik Jena, Jena, Germany). The control of $100 \%$ activity contained only the Vehicle (DMSO). For the time point 0 , the reaction was started with the addition of $\mathrm{H} 3$ peptide and ATP right after the RMS-07 transfer. The H3 and ATP concentration were $50 \mathrm{nM}$ and $18 \mu \mathrm{M}$ final concentration, respectively. The other plates received the mix H3:ATP after 1, 2, and $4 \mathrm{~h}$ incubation. The reaction was allowed to continue for $30 \mathrm{~min}$ at $28^{\circ} \mathrm{C}$ and was stopped by adding $5 \mu \mathrm{L}$ of $24 \mathrm{mM}$ EDTA in detection buffer provided in the kit (Perking Elmer). The plate was incubated for 5 min at RT, afterwards $5 \mu \mathrm{L}$ of $8 \mathrm{nM}$ of Europium-anti-phospho-Histone H3 (Thr3) was added and incubated for $1 \mathrm{~h}$ until reading. The TR-FRET signal was measured using ClarioStar microplate reader (BMG Labtech) previously set up to $340 \mathrm{~nm}$ excitation and $665 \mathrm{~nm}$ emission wavelengths, $50 \mu$ s delay time, 100 flashes, and $100 \mu$ s integration time. Data analyses were performed as detailed above.

Measurement of formation of adduct between RMS- 07 and recombinant MPS1 by liquid chromatography-mass spectrometry (LC-MS)

For routine LC-MS analysis, purified MSP1-KD $(\sim 2.0 \mathrm{mg} / \mathrm{mL})$ was diluted 50 -fold in $0.1 \%$ Formic Acid (FA) prepared in milliQ water. $10 \mu \mathrm{L}$ of the diluted protein in $0.1 \%$ FA was analyzed by reverse phase HPLC-ESI-MS using an Acquity H-class HPLC system (Waters) directly connected to a XEVO G2 SX Q-ToF (Waters). The HPLC was equipped with a C4 column (ACQUITY UPLC Protein BEH C4 Column, 300Å, $1.7 \mu \mathrm{m}, 2.1 \mathrm{~mm}$ X $100 \mathrm{~mm}$, Waters) and protein separation was performed at $35^{\circ} \mathrm{C}$. The mobile phase solvent $\mathrm{A}$ was $0.1 \% \mathrm{FA}$ in water, and solvent $\mathrm{B}$ was $0.1 \%$ FA in $100 \%$ Acetonitrile (ACN). Samples were loaded at a flow rate of $0.5 \mu \mathrm{L} / \mathrm{min}$, and eluted from the $\mathrm{C} 4$ column at a flow rate of $400 \mu \mathrm{L} / \mathrm{min}$ using two linear gradient steps: the first from 10 to $25 \%$ solvent B over $2 \mathrm{~min}$, and the second from 25 to $65 \%$ of solvent B over $7 \mathrm{~min}$. The column was regenerated by washing at $100 \% \mathrm{~B}$ for $1 \mathrm{~min}$ and re-equilibrated at $10 \%$ solvent $\mathrm{B}$ for 2 min. Exact mass analysis was performed in positive ion electrospray in resolution mode. For internal calibration, the lockspray properties were: fixed scan time of $0.5 \mathrm{sec}$ with a mass window of 0.5 Da around Leu-enkephalin (556.2771 Da). The ToF-MS acquisition ranged from $200 \mathrm{Da}$ to 3,000 Da with a scan time fixed at $0.5 \mathrm{sec}$. The cone voltage on the ESI source was 
fixed at 40 V. MS Raw data was analyzed using MassLynx (Waters) and processed by MaxEnt 1 (Waters) in order to deconvolute multi charged combined ion spectra.

To investigate the time-dependence of adduct formation, recombinant MPS1-KD was diluted in assay buffer ( $20 \mathrm{mM}$ Hepes, $\mathrm{pH} 7.5,200 \mathrm{mM} \mathrm{NaCl}$ ) to a final concentration of $2.1 \mathrm{mg} / \mathrm{mL}$. In a fresh tube, $1 \mu \mathrm{L}$ of RMS-07 (10 mM in 100\% DMSO) was added to $19 \mu \mathrm{L}$ of the diluted enzyme (final working enzyme and compound concentrations were 53.6 and $500 \mu \mathrm{M}$, respectively). The mixture was incubated at $37^{\circ} \mathrm{C}$ and flash-frozen in a liquid nitrogen bath at the following times after mixing: $1,2,4$, and $18 \mathrm{~h}$. Samples were kept at $-80^{\circ} \mathrm{C}$ until analyzed by LC-MS. Each aliquot was thawed individually and analyzed by LC-MS as described above. For each sample, total ion counts (TIC) were detected by integrating the peak corresponding to the eluted TTK at $1 / 2$ height. The integrated spectra were deconvoluted using the MaxEnt1 software (Micromass MassLynxWaters) to find the molecular weight of the multiply-charged positive ions. The normalized signal was calculated from the signals corresponding to the ratio of labelled MPS1-KD over the total MPS1-KD present. The acquired data was fitted using a non-linear regression and a single exponential equation [4] for one phase association implemented in GraphPad (v. 9.1.0).

$$
\% \text { MPS1 modified }=100 .\left(1-e^{\left(-k_{o b s} . t\right)}\right)
$$

\section{MPS1-KD crystallization and structure determination}

For co-crystallization experiments, RMS-07 was added to purified MSP1-KD (10 mg/mL) at six-fold molar excess and the mixture kept at $4{ }^{\circ} \mathrm{C}$ for 4 hours before being centrifuged at $14,000 \mathrm{rpm}$ for $10 \mathrm{~min}$ at $4{ }^{\circ} \mathrm{C}$ and used to set up 150-nL volume sitting drops at 3 different protein-inhibitor complex ratios to reservoir solution $(2: 1,1: 1$, or 1:2) with the aid of a Mosquito liquid handler (SPTLabtech). Crystallization trials were performed at $20^{\circ} \mathrm{C}$ in 3-well low-profile crystallization plates (Swissci). Optimized crystals were obtained in $0.05 \mathrm{M}$ Magnesium chloride hexahydrate; $0.05 \mathrm{M}$ Sodium Citrate Tribasic; $0.1 \mathrm{M}$ bis-Tris propane pH 7.8; 22.5\% PEG Smear High (BCS Screen - Molecular Dimensions). Crystals were cryoprotected in reservoir solution supplemented with $30 \%$ glycerol before flash-freezing in liquid nitrogen for data collection. Diffraction data were collected at $100 \mathrm{~K}$ at the Advanced Photon Source 24-ID-E. Diffraction data were integrated and scaled using XDS ${ }^{48}$ and AIMLESS (CCP4 suite) ${ }^{49}$, respectively. The structure was solved by molecular replacement using DIMPLE (CCP4 suite) ${ }^{49}$ and the kinase domain of MPS1 bound to an inhibitor Mps-BAY2b as the search model (PDB ID 5N84). Refinement was performed iteratively using Refmac (CCP4 suite) ${ }^{49}$ and $\operatorname{Coot}^{50}$ (model building and real space refinement). Structure validation was performed using Molprobity ${ }^{51}$. Structure factors and 
spatial coordinates were deposited in the PDB (Protein Data Bank) with accession code 7LQD. Data processing and refinement statistics can be found in Supplemental Table S2.

\section{Glutathione (GSH) stability}

The performed GSH-stability assay for the compound RMS-07 and Afatinib was based on a similar assay describe elsewhere ${ }^{52,53}$. Deviating from the original protocol, the reaction medium was changed to ACN/PBS-buffer 50:50. The reaction temperature was chosen to be $40{ }^{\circ} \mathrm{C}$ and reactions performed in triplicate. The reaction of RMS-07 with GSH was monitored by measuring the decreasing area under the curve $(A \cup C)$ of the compound relative to the internal standard Ibuprofen and Indoprofen (for RMS-07 and Afatinib, respectively). HPLC specifications: Column: Phenomenex Kinetex $2.6 \mathrm{u}$ C8 100A 150 x 4,6 mm. Injection volume: $5 \mu \mathrm{L}$ flow rate: $0.5 \mathrm{~mL} / \mathrm{min}$. Elution gradient $=0 \mathrm{~min}: 40 \% \mathrm{MeOH} 60 \%$ phosphate buffer $\mathrm{pH} 2.3 ; 15 \min : 85 \% \mathrm{MeOH} 15 \%$ phosphate buffer $\mathrm{pH} 2.3 ; 20 \mathrm{~min}: 85 \% \mathrm{MeOH} 15 \%$ phosphate buffer $\mathrm{pH} 2.3 ; 22 \mathrm{~min}: 40 \% \mathrm{MeOH}$ $60 \%$ phosphate buffer $\mathrm{pH} 2.3 ; 28 \mathrm{~min}: 40 \% \mathrm{MeOH} 60 \%$ phosphate buffer $\mathrm{pH} 2.3$.

\section{Microsomal stability}

Pooled liver microsomes from mice (males) were purchased from Xenotech. Incubation of RMS-07 was made in the presence of an NADPH-regenerating system (5 mM Glucose-6phosphate, $5 \mathrm{U} / \mathrm{mL}$ Glucose-6-phosphate dehydrogenase and $1 \mathrm{mM} \mathrm{NADP}{ }^{+}$). The compound RMS-07 $(100 \mu \mathrm{M})$, the NADPH-regenerating system and $4 \mathrm{mM} \mathrm{MgCl}_{2} \cdot 6 \mathrm{H}_{2} \mathrm{O}$ in $0.1 \mathrm{M}$ Tris buffer (pH 7.4) were preincubated for $5 \mathrm{~min}$ at $37^{\circ} \mathrm{C}$ and $750 \mathrm{rpm}$ on a shaker. The incubation mix was split into aliquots $(50 \mu \mathrm{L})$ and the reaction was started by the addition of mouse liver microsomes. The reaction was quenched at selected time points $(0,10,20,30,60$, and $120 \mathrm{~min})$ by adding $100 \mu \mathrm{L}$ internal standard at a concentration of $50 \mu \mathrm{M}$ in MeCN. The samples were vortexed for $30 \mathrm{~s}$ and centrifuged $\left(19.800 \mathrm{xg}\right.$ at $4{ }^{\circ} \mathrm{C}$ for $\left.15 \mathrm{~min}\right)$. The supernatant was directly used for LC-MS analysis as described below. All incubations were conducted in triplicates and a limit of $1 \%$ organic solvent was not exceeded.

Sample separation was performed on an Alliance 2695 HPLC (Waters GmbH, Eschborn) equipped with a Phenomenex Kinetex, $2.6 \mathrm{u}, \mathrm{C} 18,100 \mathrm{~A}, 100 \times 3.00 \mathrm{~mm}$ column with a $18 \mathrm{~min}$ gradient. Mobile phase A: $90 \% \mathrm{H}_{2} \mathrm{O}$ water, $10 \%$ acetonitrile and additional $0.1 \%$ formic acid $(\mathrm{v} / \mathrm{v})$, mobile phase $\mathrm{B}$ : acetonitrile with $0.1 \%$ formic acid $(\mathrm{v} / \mathrm{v})$. The gradient was set to: 0-2.5 $\min 10 \%$ B, 2.5-12.5 min from 10 to $50 \%$ B, $12.5-15 \min 50 \%$ B, 15.01 - 18 min from 50 to $10 \%$ B at a flow rate of $0.6 \mathrm{~mL} / \mathrm{min}$. Samples were maintained at $10^{\circ} \mathrm{C}$, the column temperature was set to $40^{\circ} \mathrm{C}$ with an injection volume of $5 \mu \mathrm{L}$. 
Detection was performed on a Micromass Quattro micro triple quadrupole mass spectrometer (Waters GmbH, Eschborn) using electrospray ionization in positive-mode. Spray, cone, extractor, and RF lens voltages were set to $4 \mathrm{kV}, 30 \mathrm{~V}, 5 \mathrm{~V}, 1 \mathrm{~V}$, respectively. The desolvation temperature was set to $350^{\circ} \mathrm{C}$ and the desolvation gas flow was at $650 \mathrm{~L} / \mathrm{h}$. The data was analyzed using MassLynx 4.1.

\section{Differential scanning fluorimetry (DSF) assay}

Differences in the melting temperature $\left(\Delta \mathrm{T}_{\mathrm{m}}\right)$ data were measured as described in Fedorov et $a{ }^{45}$. Purified proteins were buffered in $25 \mathrm{mM}$ HEPES ( $\mathrm{pH} 7.5$ ), $500 \mathrm{mM} \mathrm{NaCl}$ and were assayed in a 384-wellplate with a final protein concentration of $2 \mu \mathrm{M}$ in $10 \mu \mathrm{L}$ assay volume. Inhibitors were added to a final concentration of $10 \mu \mathrm{M}$, using an ECHO 550 acoustic dispenser (Labcyte). As a fluorescence probe, SYPRO-Orange (Molecular Probes) was added in a 1:5000 dilution. Filters for excitation and emission were set to $465 \mathrm{~nm}$ and $590 \mathrm{~nm}$, respectively. The temperature was increased from $25^{\circ} \mathrm{C}$ with $3^{\circ} \mathrm{C} / \mathrm{min}$ to a final temperature of $95^{\circ} \mathrm{C}$, while scanning, using the QuantStudio5 (Applied Biosystems). Data was analyzed through Boltzmannequation in the Protein Thermal Shift software (Applied Biosystems). Samples were measured in technical duplicates.

\section{Associated content}

\section{Supporting Information}

The Supporting Information is available for download on this website.

\section{ORCID}

Ricardo A. M. Serafim: 0000-0003-0614-1798

André S. Santiago: 0000-0002-3973-3370

Caio V. dos Reis: 0000-0001-6271-7523

Jessica E. Takarada: 0000-0001-7311-8665

Priscila Mezzomo: 0000-0001-7331-7664

Katlin B. Massirer: 0000-0001-6390-2560

Martin Schwalm: 0000-0002-1252-1829

Mark Kudolo: -

Stefan Gerstenecker: -

Apirat Chaikuad: 0000-0003-1120-2209

Stefan Knapp: 0000-0001-5995-6494

Stefan Laufer: 0000-0001-6952-1486

Rafael M. Couñago: 0000-0003-1847-5090

Matthias Gehringer: 0000-0003-0163-3419 


\section{Author Contributions}

Initial conceptualization: M.G.;

Covalent inhibitor design: M.G. and R.A.M.S.;

Synthetic and analytical chemistry: R.A.M.S., M.G. and S.G.;

Recombinant protein production: A.S.S. (design, analysis and execution);

Enzymatic assays (IC $\mathrm{C}_{50}, K_{\mathrm{i}}$, and $K_{\mathrm{l}} / k_{\text {inact }}$ determination) and LC-MS-based assays ( $k_{\text {obs }}$ determination): R.M.C (design and analysis), A.S.S. (design, analysis and execution);

Protein crystallization and structure determination: R.M.C (design and analysis), C.V.R. (design, analysis and execution);

DSF selectivity panel assays: M.P.S., A.C. and S.K.;

Glutathione stability: R.A.M.S. and S.G.;

Microsomal stability: M.K.;

Manuscript writing - original draft preparation: R.A.M.S., R.M.C., and M.G.;

Manuscript writing - review and editing: all authors

Project coordination: R.M.C., K.B.M, S.K., S.L. and M.G.

\section{Funding Sources}

Part of this work was funded by Fundação de Amparo à Pesquisa do Estado de São Paulo (FAPESP; grant numbers: 2013/50724-5 and 2014/50897-0) and CNPq (Conselho Nacional de Desenvolvimento Científico e Tecnológico; grant number: 465651/2014-3). R.A.M.S. (2016/25320-6 and 2018/23322-7) and A.S.S. (2019/14275-8) were the recipient of FAPESP postdoctoral fellowships. R.A.M.S. is recipient of the University of Tübingen "Teach@Tübingen" fellowship. C.V.R was the recipient of a CAPES fellowship (Coordenação de Aperfeiçoamento de Pessoal de Nível Superior; 88887.146077/2017-00).

S.K., A.C. and M.P.S. are grateful for support by the SGC, a registered charity (no: 1097737) that receives funds from AbbVie, Bayer AG, Boehringer Ingelheim, Canada Foundation for Innovation, Eshelman Institute for Innovation, Genentech, Genome Canada through Ontario Genomics Institute [OGI-196], EU/EFPIA/OICR/McGill/KTH/Diamond, Innovative Medicines Initiative 2 Joint Undertaking [EUbOPEN grant 875510], Janssen, Merck KGaA, Merck \& Co, Pfizer, São Paulo Research Foundation-FAPESP, Takeda and Wellcome. S.K. is also grateful for funding by the German translational cancer network (DKTK) the Frankfurt Cancer Centre (FCI). M.G. gratefully acknowledges financial support of this project by the Institutional Strategy of the University of Tübingen (ZUK 63, German Research Foundation), the RiSC Program of the State Ministry of Baden-Württemberg for Sciences, Research and Arts, and the Postdoctoral Fellowship Program of the Baden-Württemberg Stiftung. Funding by the German Research Foundation (Deutsche Forschungsgemeinschaft, DFG) under Germany's Excellence Strategy-EXC $2180-390900677$ is further acknowledged by S.L. and M.G..

\section{Notes}

The authors declare no competing financial interest.

\section{Acknowledgments}

We thank the staff of the Life Sciences Core Facility (LACTAD) at UNICAMP for the Genomics and Proteomics analysis. This work is based upon research conducted at the Northeastern Collaborative Access Team beamlines, which are funded by the National Institute of General 
Medical Sciences from the National Institutes of Health (P30 GM124165). The Eiger 16M detector on the 24-ID-E beam line is funded by a NIH-ORIP HEI grant (S10OD021527). This research used resources of the Advanced Photon Source, a U.S. Department of Energy (DOE) Office of Science User Facility operated for the DOE Office of Science by Argonne National Laboratory under Contract No. DE-AC02-06CH11357.

\section{References}

(1) Primorac, I.; Weir, J. R.; Chiroli, E.; Gross, F.; Hoffmann, I.; van Gerwen, S.; Ciliberto, A.; Musacchio, A. Bub3 Reads Phosphorylated MELT Repeats to Promote Spindle Assembly Checkpoint Signaling. Elife 2013, 2, e01030. https://doi.org/10.7554/eLife.01030.

(2) Shepperd, L. A.; Meadows, J. C.; Sochaj, A. M.; Lancaster, T. C.; Zou, J.; Buttrick, G. J.; Rappsilber, J.; Hardwick, K. G.; Millar, J. B. A. Phosphodependent Recruitment of Bub1 and Bub3 to Spc7/KNL1 by Mph1 Kinase Maintains the Spindle Checkpoint. Curr. Biol. 2012, 22 (10), 891-899. https://doi.org/10.1016/j.cub.2012.03.051.

(3) Yamagishi, Y.; Yang, C.-H.; Tanno, Y.; Watanabe, Y.; Shepperd, L. A.; Meadows, J. C.; Sochaj, A. M.; Lancaster, T. C.; Zou, J.; Buttrick, G. J.; et al. MPS1/Mph1 Phosphorylates the Kinetochore Protein KNL1/Spc7 to Recruit SAC Components. Curr. Biol. 2012, 14 (10), e01030. https://doi.org/10.1038/ncb2515.

(4) Jelluma, N.; Brenkman, A. B.; van den Broek, N. J. F.; Cruijsen, C. W. A.; van Osch, M. H. J.; Lens, S. M. A.; Medema, R. H.; Kops, G. J. P. L. Mps1 Phosphorylates Borealin to Control Aurora B Activity and Chromosome Alignment. Cell 2008, 132 (2), 233-246. https://doi.org/10.1016/j.cell.2007.11.046.

(5) Tighe, A.; Staples, O.; Taylor, S. Mps1 Kinase Activity Restrains Anaphase during an Unperturbed Mitosis and Targets Mad2 to Kinetochores. J. Cell Biol. 2008, 181 (6), 893-901. https://doi.org/10.1083/jcb.200712028.

(6) Hogg, D.; Guidos, C.; Bailey, D.; Amendola, A.; Groves, T.; Davidson, J.; Schmandt, R.; Mills, G. Cell Cycle Dependent Regulation of the Protein Kinase TTK. Oncogene 1994, 9 (1), 89-96.

(7) Carter, S. L.; Eklund, A. C.; Kohane, I. S.; Harris, L. N.; Szallasi, Z. A Signature of Chromosomal Instability Inferred from Gene Expression Profiles Predicts Clinical Outcome in Multiple Human Cancers. Nat. Genet. 2006, 38 (9), 1043-1048. https://doi.org/10.1038/ng1861. 
(8) Simon Serrano, S.; Sime, W.; Abassi, Y.; Daams, R.; Massoumi, R.; Jemaà, M. Inhibition of Mitotic Kinase Mps1 Promotes Cell Death in Neuroblastoma. Sci. Rep. 2020, 10 (1), 11997. https://doi.org/10.1038/s41598-020-68829-y.

(9) Janssen, A.; Kops, G. J.; Medema, R. H. Targeting the Mitotic Checkpoint to Kill Tumor Cells. Horm. Cancer 2011, 2 (2), 113-116. https://doi.org/10.1007/s12672-010-0059-x.

(10) Jemaà, M.; Galluzzi, L.; Kepp, O.; Senovilla, L.; Brands, M.; Boemer, U.; Koppitz, M.; Lienau, P.; Prechtl, S.; Schulze, V.; et al. Characterization of Novel MPS1 Inhibitors with Preclinical Anticancer Activity. Cell Death Differ. 2013, 20 (11), 1532-1545. https://doi.org/10.1038/cdd.2013.105.

(11) Schulze, V. K.; Klar, U.; Kosemund, D.; Wengner, A. M.; Siemeister, G.; Stöckigt, D.; Neuhaus, R.; Lienau, P.; Bader, B.; Prechtl, S.; et al. Treating Cancer by Spindle Assembly Checkpoint Abrogation: Discovery of Two Clinical Candidates, BAY 1161909 and BAY 1217389, Targeting MPS1 Kinase. J. Med. Chem. 2020, 63 (15), 8025-8042. https://doi.org/10.1021/acs.jmedchem.9b02035.

(12) Woodward, H. L.; Innocenti, P.; Cheung, K.-M. J.; Hayes, A.; Roberts, J.; Henley, A. T.; Faisal, A.; Mak, G. W.-Y.; Box, G.; Westwood, I. M.; et al. Introduction of a Methyl Group Curbs Metabolism of Pyrido[3,4- d]Pyrimidine Monopolar Spindle 1 (MPS1) Inhibitors and Enables the Discovery of the Phase 1 Clinical Candidate N(2)-(2-Ethoxy-4-(4-Methyl4 H-1,2,4-Triazol-3-Yl)Phenyl)-6-Methyl- N(8)-Neopentylpyrido[3,4-d]pyrimidine-2,8diamine (BOS172722). J. Med. Chem. 2018, 61 (18), 8226-8240. https://doi.org/10.1021/acs.jmedchem.8b00690.

(13) Mason, J. M.; Wei, X.; Fletcher, G. C.; Kiarash, R.; Brokx, R.; Hodgson, R.; Beletskaya, I.; Bray, M. R.; Mak, T. W. Functional Characterization of CFI-402257, a Potent and Selective Mps1/TTK Kinase Inhibitor, for the Treatment of Cancer. Proc. Natl. Acad. Sci. U. S. A. 2017, 114 (12), 3127-3132. https://doi.org/10.1073/pnas.1700234114.

(14) Cohen, P.; Alessi, D. R. Kinase Drug Discovery--What's next in the Field? ACS Chem. Biol. 2013, 8 (1), 96-104. https://doi.org/10.1021/cb300610s.

(15) Copeland, R. A.; Pompliano, D. L.; Meek, T. D. Drug-Target Residence Time and Its Implications for Lead Optimization. Nat. Rev. Drug Discov. 2006, 5 (9), 730-739. https://doi.org/10.1038/nrd2082.

(16) Georgi, V.; Schiele, F.; Berger, B.-T.; Steffen, A.; Marin Zapata, P. A.; Briem, H.; Menz, S.; 
Preusse, C.; Vasta, J. D.; Robers, M. B.; et al. Binding Kinetics Survey of the Drugged Kinome. J. Am. Chem. Soc. 2018, 140 (46), 15774-15782.

https://doi.org/10.1021/jacs.8b08048.

(17) Dahl, G.; Akerud, T. Pharmacokinetics and the Drug-Target Residence Time Concept. Drug Discov. Today 2013, 18 (15-16), 697-707.

https://doi.org/10.1016/j.drudis.2013.02.010.

(18) Singh, J.; Petter, R. C.; Baillie, T. A.; Whitty, A. The Resurgence of Covalent Drugs. Nat. Rev. Drug Discov. 2011, 10 (4), 307-317. https://doi.org/10.1038/nrd3410.

(19) Barf, T.; Kaptein, A. Irreversible Protein Kinase Inhibitors: Balancing the Benefits and Risks. J. Med. Chem. 2012, 55 (14), 6243-6262. https://doi.org/10.1021/jm3003203.

(20) Chaikuad, A.; Koch, P.; Laufer, S. A.; Knapp, S. The Cysteinome of Protein Kinases as a Target in Drug Development. Angew. Chem. Int. Ed. Engl. 2018, 57 (16), 4372-4385. https://doi.org/10.1002/anie.201707875.

(21) Abdeldayem, A.; Raouf, Y. S.; Constantinescu, S. N.; Moriggl, R.; Gunning, P. T. Advances in Covalent Kinase Inhibitors. Chem. Soc. Rev. 2020, 49 (9), 2617-2687. https://doi.org/10.1039/c9cs00720b.

(22) Gehringer, M. Covalent Kinase Inhibitors: An Overview. In Topics in Medicinal Chemistry; Springer: Berlin/Heidelberg, Germany, 2020; pp 1-52. https://doi.org/10.1007/7355_2020_103.

(23) Roskoski, R. J. Orally Effective FDA-Approved Protein Kinase Targeted Covalent Inhibitors (TCls). Pharmacol. Res. 2021, 105422. https://doi.org/10.1016/j.phrs.2021.105422.

(24) Gehringer, M.; Laufer, S. A. Emerging and Re-Emerging Warheads for Targeted Covalent Inhibitors: Applications in Medicinal Chemistry and Chemical Biology. J. Med. Chem. 2019, 62 (12), 5673-5724. https://doi.org/10.1021/acs.jmedchem.8b01153.

(25) Gehringer, M. Covalent Inhibitors: Back on Track? Future Med. Chem. 2020, 12 (15) 1363-1368. https://doi.org/10.4155/fmc-2020-0118.

(26) Uitdehaag, J. C. M.; de Man, J.; Willemsen-Seegers, N.; Prinsen, M. B. W.; Libouban, M. A. A.; Sterrenburg, J. G.; de Wit, J. J. P.; de Vetter, J. R. F.; de Roos, J. A. D. M.; Buijsman, R. C.; et al. Target Residence Time-Guided Optimization on TTK Kinase Results in Inhibitors with Potent Anti-Proliferative Activity. J. Mol. Biol. 2017, 429 (14), 2211- 
2230. https://doi.org/10.1016/j.jmb.2017.05.014.

(27) Colombo, R.; Caldarelli, M.; Mennecozzi, M.; Giorgini, M. L.; Sola, F.; Cappella, P.; Perrera, C.; Depaolini, S. R.; Rusconi, L.; Cucchi, U.; et al. Targeting the Mitotic Checkpoint for Cancer Therapy with NMS-P715, an Inhibitor of MPS1 Kinase. Cancer Res. 2010, 70 (24), 10255-10264. https://doi.org/10.1158/0008-5472.CAN-10-2101.

(28) Wang, S.; Zhang, M.; Liang, D.; Sun, W.; Zhang, C.; Jiang, M.; Liu, J.; Li, J.; Li, C.; Yang, X.; et al. Molecular Design and Anticancer Activities of Small-Molecule Monopolar Spindle 1 Inhibitors: A Medicinal Chemistry Perspective. Eur. J. Med. Chem. 2019, 175, 247268. https://doi.org/10.1016/j.ejmech.2019.04.047.

(29) Huang, M.; Huang, Y.; Guo, J.; Yu, L.; Chang, Y.; Wang, X.; Luo, J.; Huang, Y.; Tu, Z.; Lu, X.; et al. Pyrido[2, 3-d]Pyrimidin-7(8H)-Ones as New Selective Orally Bioavailable Threonine Tyrosine Kinase (TTK) Inhibitors. Eur. J. Med. Chem. 2020, 113023. https://doi.org/10.1016/j.ejmech.2020.113023.

(30) Hagel, M.; Miduturu, C.; Sheets, M.; Rubin, N.; Weng, W.; Stransky, N.; Bifulco, N.; Kim, J. L.; Hodous, B.; Brooijmans, N.; et al. First Selective Small Molecule Inhibitor of FGFR4 for the Treatment of Hepatocellular Carcinomas with an Activated FGFR4 Signaling Pathway. Cancer Discov. 2015, 5 (4), 424-437. https://doi.org/10.1158/2159-8290.CD14-1029.

(31) Kim, R. D.; Sarker, D.; Meyer, T.; Yau, T.; Macarulla, T.; Park, J.-W.; Choo, S. P.; Hollebecque, A.; Sung, M. W.; Lim, H.-Y.; et al. First-in-Human Phase I Study of Fisogatinib (BLU-554) Validates Aberrant FGF19 Signaling as a Driver Event in Hepatocellular Carcinoma. Cancer Discov. 2019, 9 (12), 1696-1707. https://doi.org/10.1158/2159-8290.CD-19-0555.

(32) Joshi, J. J.; Coffey, H.; Corcoran, E.; Tsai, J.; Huang, C.-L.; Ichikawa, K.; Prajapati, S.; Hao, M.-H.; Bailey, S.; Wu, J.; et al. H3B-6527 Is a Potent and Selective Inhibitor of FGFR4 in FGF19-Driven Hepatocellular Carcinoma. Cancer Res. 2017, 77 (24), 6999-7013. https://doi.org/10.1158/0008-5472.CAN-17-1865.

(33) Kwiatkowski, N.; Jelluma, N.; Filippakopoulos, P.; Soundararajan, M.; Manak, M. S.; Kwon, M.; Choi, H. G.; Sim, T.; Deveraux, Q. L.; Rottmann, S.; et al. Small-Molecule Kinase Inhibitors Provide Insight into Mps1 Cell Cycle Function. Nat. Chem. Biol. 2010, 6 (5), 359-368. https://doi.org/10.1038/nchembio.345. 
(34) De Man, A. P. A.; Buijsman, R. C.; Sterrenburg, J. G.; Uitdehaag, J. C. M.; De Wit, J. J. P.; Zaman, G. J. R. (5,6-Dihydro)Pyrimido[4,5-E]Indolizines. International Publication Number: Patent WO2015/155042A1, October 15, 2015.

(35) De Roos, J.; Uitdehaag, J. C. M.; De Man, A. P. A.; Buijsman, R. C.; Zaman, G. J. Prognostic Biomarkers for TTK Inhibitors Chemotherapy. International Publication Number: Patent WO2016/166255A1, October 20, 2016.

(36) Maia, A. R. R.; de Man, J.; Boon, U.; Janssen, A.; Song, J.-Y.; Omerzu, M.; Sterrenburg, J. G.; Prinsen, M. B. W.; Willemsen-Seegers, N.; de Roos, J. A. D. M.; et al. Inhibition of the Spindle Assembly Checkpoint Kinase TTK Enhances the Efficacy of Docetaxel in a TripleNegative Breast Cancer Model. Ann. Oncol. Off. J. Eur. Soc. Med. Oncol. 2015, 26 (10), 2180-2192. https://doi.org/10.1093/annonc/mdv293.

(37) Yung-Chi, C.; Prusoff, W. H. Relationship between the Inhibition Constant (KI) and the Concentration of Inhibitor Which Causes 50 per Cent Inhibition (150) of an Enzymatic Reaction. Biochem. Pharmacol. 1973, 22 (23), 3099-3108. https://doi.org/10.1016/0006-2952(73)90196-2.

(38) Krippendorff, B. F.; Neuhaus, R.; Lienau, P.; Reichel, A.; Huisinga, W. Mechanism-Based Inhibition: Deriving Kiand Kinact Directly from Time-Dependent Ic50 Values. J. Biomol. Screen. 2009, 14 (8), 913-923. https://doi.org/10.1177/1087057109336751.

(39) De Cesco, S.; Kurian, J.; Dufresne, C.; Mittermaier, A. K.; Moitessier, N. Covalent Inhibitors Design and Discovery. Eur. J. Med. Chem. 2017, 138, 96-114. https://doi.org/10.1016/j.ejmech.2017.06.019.

(40) Yan, Z.; Rafferty, B.; Caldwell, G. W.; Masucci, J. A. Rapidly Distinguishing Reversible and Irreversible CYP450 Inhibitors by Using Fluorometric Kinetic Analyses. Eur. J. Drug Metab. Pharmacokinet. 2002, 27 (4), 281-287. https://doi.org/10.1007/BF03192339.

(41) Schwartz, P. A.; Kuzmic, P.; Solowiej, J.; Bergqvist, S.; Bolanos, B.; Almaden, C.; Nagata, A.; Ryan, K.; Feng, J.; Dalvie, D.; et al. Covalent EGFR Inhibitor Analysis Reveals Importance of Reversible Interactions to Potency and Mechanisms of Drug Resistance. Proc. Natl. Acad. Sci. U. S. A. 2014, 111 (1), 173-178. https://doi.org/10.1073/pnas.1313733111.

(42) Birkholz, A.; Kopecky, D. J.; Volak, L. P.; Bartberger, M. D.; Chen, Y.; Tegley, C. M.; Arvedson, T.; McCarter, J. D.; Fotsch, C.; Cee, V. J. Systematic Study of the Glutathione 
Reactivity of N-Phenylacrylamides: 2. Effects of Acrylamide Substitution. J. Med. Chem. 2020, 63 (20), 11602-11614. https://doi.org/10.1021/acs.jmedchem.0c00749.

(43) Robers, M. B.; Dart, M. L.; Woodroofe, C. C.; Zimprich, C. A.; Kirkland, T. A.; Machleidt, T.; Kupcho, K. R.; Levin, S.; Hartnett, J. R.; Zimmerman, K.; et al. Target Engagement and Drug Residence Time Can Be Observed in Living Cells with BRET. Nat. Commun. 2015, 6 (May), 10091. https://doi.org/10.1038/ncomms10091.

(44) Kim, J. A.; Tan, Y.; Wang, X.; Cao, X.; Veeraraghavan, J.; Liang, Y.; Edwards, D. P.; Huang, S.; Pan, X.; Li, K.; et al. Comprehensive Functional Analysis of the Tousled-like Kinase 2 Frequently Amplified in Aggressive Luminal Breast Cancers. Nat. Commun. 2016, 7, 117. https://doi.org/10.1038/ncomms12991.

(45) Fedorov, O.; Niesen, F. H.; Knapp, S. Kinase Inhibitor Selectivity Profiling Using Differential Scanning Fluorimetry. Methods Mol. Biol. 2012, 795, 109-118. https://doi.org/10.1007/978-1-61779-337-0_7.

(46) Anastassiadis, T.; Deacon, S. W.; Devarajan, K.; Ma, H.; Peterson, J. R. Comprehensive Assay of Kinase Catalytic Activity Reveals Features of Kinase Inhibitor Selectivity. Nat. Biotechnol. 2011, 29 (11), 1039-1045. https://doi.org/10.1038/nbt.2017.

(47) Savitsky, P.; Bray, J.; Cooper, C. D. O.; Marsden, B. D.; Mahajan, P.; Burgess-Brown, N. A.; Gileadi, O. High-Throughput Production of Human Proteins for Crystallization: The SGC Experience. J. Struct. Biol. 2010, 172 (1), 3-13. https://doi.org/10.1016/j.jsb.2010.06.008.

(48) Kabsch, W. XDS. Acta Crystallogr. D. Biol. Crystallogr. 2010, 66 (Pt 2), 125-132. https://doi.org/10.1107/S0907444909047337.

(49) Winn, M. D.; Ballard, C. C.; Cowtan, K. D.; Dodson, E. J.; Emsley, P.; Evans, P. R.; Keegan, R. M.; Krissinel, E. B.; Leslie, A. G. W.; McCoy, A.; et al. Overview of the CCP4 Suite and Current Developments. Acta Crystallogr. D. Biol. Crystallogr. 2011, 67 (Pt 4), 235-242. https://doi.org/10.1107/\$0907444910045749.

(50) Emsley, P.; Lohkamp, B.; Scott, W. G.; Cowtan, K. Features and Development of Coot. Acta Crystallogr. D. Biol. Crystallogr. 2010, 66 (Pt 4), 486-501. https://doi.org/10.1107/S0907444910007493.

(51) Chen, V. B.; Arendall, W. B. 3rd; Headd, J. J.; Keedy, D. A.; Immormino, R. M.; Kapral, G. J.; Murray, L. W.; Richardson, J. S.; Richardson, D. C. MolProbity: All-Atom Structure 
Validation for Macromolecular Crystallography. Acta Crystallogr. D. Biol. Crystallogr. 2010, 66 (Pt 1), 12-21. https://doi.org/10.1107/S0907444909042073.

(52) Keeley, A.; Ábrányi-Balogh, P.; Keserü, G. M. Design and Characterization of a Heterocyclic Electrophilic Fragment Library for the Discovery of Cysteine-Targeted Covalent Inhibitors. MedChem Comm 2019, 10 (2), 263-267. https://doi.org/10.1039/c8md00327k.

(53) Forster, M.; Liang, X. J.; Schröder, M.; Gerstenecker, S.; Chaikuad, A.; Knapp, S.; Laufer, S.; Gehringer, M. Discovery of a Novel Class of Covalent Dual Inhibitors Targeting the Protein Kinases BMX and BTK. Int. J. Mol. Sci. 2020, 21 (23). https://doi.org/10.3390/ijms21239269. 